\title{
MIROC-ESM 2010: model description and basic results of CMIP5-20c3m experiments
}

\author{
S. Watanabe ${ }^{1}$, T. Hajima ${ }^{1}$, K. Sudo ${ }^{2}$, T. Nagashima ${ }^{3}$, T. Takemura ${ }^{4}$, H. Okajima ${ }^{1}$, T. Nozawa ${ }^{2,3}$, H. Kawase ${ }^{3}$,

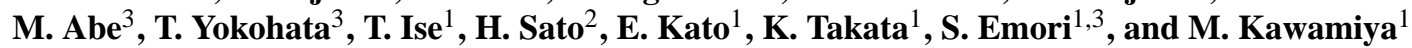 \\ ${ }^{1}$ Japan Agency for Marine-Earth Science and Technology, Yokohama, Japan \\ ${ }^{2}$ Graduate School of Environmental Studies, Nagoya University, Nagoya, Japan \\ ${ }^{3}$ National Institute for Environmental Studies, Tsukuba, Japan \\ ${ }^{4}$ Research Institute for Applied Mechanics, Kyushu University, Kasuga, Japan
}

Received: 25 April 2011 - Published in Geosci. Model Dev. Discuss.: 17 May 2011

Revised: 14 September 2011 - Accepted: 16 September 2011 - Published: 4 October 2011

\begin{abstract}
An earth system model (MIROC-ESM 2010) is fully described in terms of each model component and their interactions. Results for the CMIP5 (Coupled Model Intercomparison Project phase 5) historical simulation are presented to demonstrate the model's performance from several perspectives: atmosphere, ocean, sea-ice, land-surface, ocean and terrestrial biogeochemistry, and atmospheric chemistry and aerosols. An atmospheric chemistry coupled version of MIROC-ESM (MIROC-ESM-CHEM 2010) reasonably reproduces transient variations in surface air temperatures for the period $1850-2005$, as well as the presentday climatology for the zonal-mean zonal winds and temperatures from the surface to the mesosphere. The historical evolution and global distribution of column ozone and the amount of tropospheric aerosols are reasonably simulated in the model based on the Representative Concentration Pathways' (RCP) historical emissions of these precursors. The simulated distributions of the terrestrial and marine biogeochemistry parameters agree with recent observations, which is encouraging to use the model for future global change projections.
\end{abstract}

\section{Introduction}

The establishment of long-term mitigation goals against climate change should be based on sound information from scientific projections on a centennial time scale. Tools that have been developed for reliable projection include numerical climate models (e.g. K-1 model developers, 2004), future scenarios (Moss et al., 2010), and model experimental design

Correspondence to: $\mathrm{S}$. Watanabe

(wnabe@jamstec.go.jp)
(Hibbard et al., 2007; Meehl and Hibbard, 2007; Taylor et al., 2009). These efforts are mutually cooperative and expected to enhance collaboration among different communities working on model development, impact assessment and scenario development (Moss et al., 2010). Projections made up to year 2300 using this approach will aid the refinement of policies for greenhouse gas (GHG) reduction by, say, 2050 (Miyama and Kawamiya, 2009).

Interactions between climate change and biogeochemical processes should be taken into account when performing centennial projections. Cox et al. (2000) pointed out that there could be a significant positive feedback between climate change and the carbon cycle, implying that future temperature rise projected by "traditional" climate models without a built-in carbon cycle may have been underestimated. Further study is needed on this issue because the strength of the feedback shows complex spatial variability (Yoshikawa et al., 2008), varies considerably among different models (Friedlingstein et al., 2006) and may be altered by incorporation of novel processes as suggested by recent studies (Bonan, 2008). Moreover, the behavior of atmospheric constituents such as tropospheric and stratospheric ozone may trigger changes in the carbon cycle (Sitch et al., 2007; Le Quéré et al., 2007; Lenton et al., 2009). Furthermore, some phenomena that involve stratospheric processes, such as ozone and water vapor exchange between the stratosphere and troposphere, could have a significant impact on the surface climate (Sudo et al., 2003; Solomon et al., 2010). It is therefore desirable that comprehensive models for global change projection represent the dynamics of non$\mathrm{CO}_{2}$ GHGs, as well as that of carbon, with a sophisticated treatment of the stratosphere.

Published by Copernicus Publications on behalf of the European Geosciences Union. 


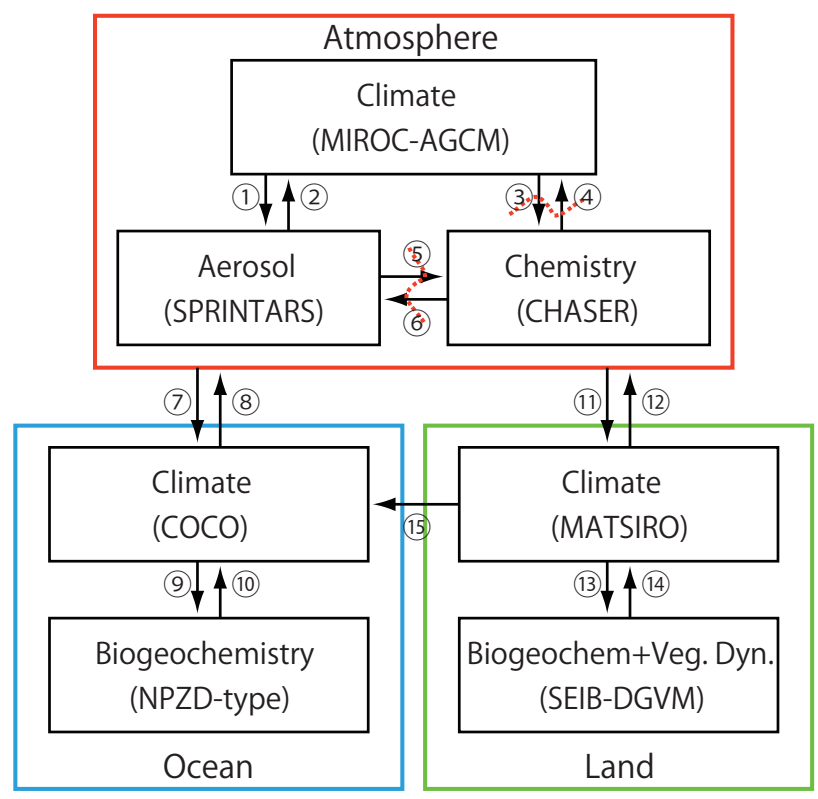

Fig. 1. Structure of MIROC-ESM. The numbers refer to the variables in Table 1.

In response to these issues, earth system models (ESMs), which is often used as a synonym for coupled climate models with biogeochemical components, are now being developed at leading institutes for climate science (e.g. Tjiputra et al., 2010; Weaver et al., 2001; Hill et al., 2004; Redler et al., 2010). This work describes the structure and performances of an ESM developed on the basis of the version presented by Kawamiya et al. (2005) at the Japan Agency for MarineEarth Science and Technology (JAMSTEC) in collaboration with, among others, the University of Tokyo and the National Institute for Environmental Studies (NIES).

\section{Model description}

Our ESM, named "MIROC-ESM", is based on a global climate model MIROC (Model for Interdisciplinary Research on Climate) which has been cooperatively developed by the University of Tokyo, NIES, and JAMSTEC (K-1 model developers, 2004; Nozawa et al., 2007). A comprehensive atmospheric general circulation model (MIROC-AGCM 2010) including an on-line aerosol component (SPRINTARS 5.00), an ocean GCM with sea-ice component (COCO 3.4), and a land surface model (MATSIRO) are interactively coupled in MIROC as illustrated in Fig. 1. These atmosphere, ocean, and land surface components, as well as a river routing scheme, are coupled by a flux coupler (K-1 model developers, 2004).

On the basis of MIROC, MIROC-ESM further includes an atmospheric chemistry component (CHASER 4.1), a nutrient-phytoplankton-zooplankton-detritus (NPZD) type ocean ecosystem component, and a terrestrial ecosystem component dealing with dynamic vegetation (SEIB-DGVM). Table 1 shows the modeled variables that are exchanged among the components of MIROC-ESM, and the numbered arrows in Fig. 1 indicate the pathways of these variables.

Due to given large uncertainty in coupling processes, the present version of MIROC-ESM includes some limited processes, only: e.g. effects of vegetation changes on dust emission, and effects of deposition of black carbon (BC) and dust on snow albedo (see Sect. 2.3.1). Many coupling processes, which are potentially important in the Earth system, are not included at present. For example: the atmospheric chemistry and aerosols are not directly coupled with ecosystems at present. Biogenic emissions of dimethylsulfide (DMS) do not depend on the ocean biogeochemistry. Vegetation changes do not affect biogenic emissions of atmospheric compositions including ozone and aerosol precursors, though changes in biogenic volatile organic compounds (VOCs) due to land use change could be effective in the corresponding regions in the real world (Sudo et al., 2010). Ozone and other ecologically harmful gases and acids, and ultraviolet radiation do not damage ecosystems.

As a total integration period of many thousands of years was requested for the series of CMIP5 (Coupled Model Intercomparison Project phase-5) experiments on long-term future climate projections (Taylor et al., 2009), the number of experiments that would be performed with the full version of MIROC-ESM had to be limited. Therefore, a limited number of experiments were performed using the CHASER-coupled version of MIROC-ESM (MIROC-ESM-CHEM), while all of the requested experiments were performed using a version without the coupled atmospheric chemistry, referred to as MIROC-ESM hereafter. In later literatures the present version of MIROC-ESM and MIROC-ESM-CHEM would be referred to with the year 2010 like "MIROC-ESM 2010". By comparing results of these two versions, the importance of chemistry climate interactions on the transient climate system may be estimated, although this is beyond the scope of the present paper. Each component of MIROC-ESM-CHEM will be described in the following subsections.

\subsection{Atmospheric model}

\subsubsection{MIROC-AGCM}

The atmospheric general circulation model (MIROCAGCM) is based on the previous CCSR (Center for Climate System Research, University of Tokyo)/NIES/FRCGC (Frontier Research Center for Global Change, JAMSTEC) AGCM (K-1 model developers, 2004; Nozawa et al., 2007). The MIROC-AGCM has a spectral dynamical core, and uses a flux-form semi-Lagrangian scheme for the tracer advection. The horizontal triangular truncation at a total horizontal wave number of 42 (T42; equivalent grid interval is approximately 2.8125 degrees in latitude and longitude) is used 
Table 1. Variables exchanged between each model component.

\begin{tabular}{|c|}
\hline Within Atmosphere \\
\hline (1) Climate (MIROC-AGCM) $\Rightarrow$ Aerosols (SPRINTARS) \\
\hline $\begin{array}{l}\text { Specific Humidity } \\
\text { Mass Mixing Ratio of Cloud (Water plus Ice) } \\
\text { Mass Mixing Ratio of Aerosols (Each Component) } \\
\text { Cloud Droplet Number Concentration } \\
\text { Ice Crystal Number Concentration } \\
\text { Surface Air Pressure } \\
\text { Air Temperature } \\
\text { Surface Altitude } \\
\text { Land Area Fraction } \\
\text { Near-Surface Air Temperature } \\
\text { Eastward Near-Surface Wind Speed } \\
\text { Northward Near-Surface Wind Speed } \\
\text { Diffusion Coefficient } \\
\text { Near-Surface Wind Speed due to Dry Convection } \\
\text { Omega } \\
\text { Solar Zenith Angle } \\
\text { Soil Moisture } \\
\text { Snow Amount } \\
\text { Surface Downwelling Shortwave Radiation } \\
\text { Sea Ice Concentration } \\
\text { Total Cloud Fraction } \\
\text { Leaf Area Index } \\
\text { Precipitation } \\
\text { Convective Cloud Area Fraction } \\
\text { Stratiform Cloud Area Fraction } \\
\text { Mass Mixing Ratio of Cloud Liquid Water } \\
\text { Mass Mixing Ratio of Cloud Ice } \\
\text { Mass Fraction of Cloud Liquid Water } \\
\text { Tendency of Air Temperature due to Radiative Heating } \\
\text { time } \\
\text { time step }\end{array}$ \\
\hline (2) Aerosols (SPRINTARS) $\Rightarrow$ Climate (MIROC-AGCM) \\
\hline $\begin{array}{l}\text { Specific Humidity } \\
\text { Mass Mixing Ratio of Cloud (Water plus Ice) } \\
\text { Mass Mixing Ratio of Aerosols (Each Component) } \\
\text { Cloud Droplet Number Concentration } \\
\text { Ice Crystal Number Concentration } \\
\text { Mass Mixing Ratio of Aerosols for Radiation Code }\end{array}$ \\
\hline (3) Climate (MIROC-AGCM) $\Rightarrow$ Chemistry (CHASER) \\
\hline $\begin{array}{l}\text { Air temperature (3-D \& surface) } \\
\text { Specific humidity } \\
\text { Relative humidity } \\
\text { Eastward wind } \\
\text { Northward wind } \\
\text { Vertical wind } \\
\text { Convective mass flux } \\
\text { cloud area fraction (3-D \& surface) } \\
\text { atmosphere cloud condensed water content } \\
\text { atmosphere cloud ice content } \\
\text { precipitation flux (3-D \& surface) } \\
\text { snowfall flux (3-D \& surface) }\end{array}$ \\
\hline
\end{tabular}


Table 1. Continued.

convective precipitation flux

tendency of cloud condensed water content

tendency of cloud ice content

subgrid diffusion coefficients

upward shortwave flux (3-D \& surface)

downward shortwave flux (3-D \& surface)

(4) Chemistry (CHASER) $\Rightarrow$ Climate (MIROC-AGCM)

specific humidity

mole fraction of $\mathrm{O}_{3}$ in air

mole fraction of $\mathrm{CH}_{4}$ in air

mole fraction of $\mathrm{N}_{2} \mathrm{O}$ in air

mole fraction of Halocarbons in air

(5) Aerosols (SPRINTARS) $\Rightarrow$ Chemistry (CHASER)

aerosol surface density in air

mole fraction of dust aerosol in air

(6) Chemistry (CHASER) $\Rightarrow$ Aerosols (SPRINTARS)

mole fraction of $\mathrm{OH}$ in air

mole fraction of $\mathrm{O}_{3}$ in air

mole fraction of $\mathrm{H}_{2} \mathrm{O}_{2}$ in air

\#mole fraction \& number density of $\mathrm{SO}_{4}$ in air

\#mole fraction \& number density of aerosol nitrate in air

\#mole fraction \& number density of SOA in air

\#aerosol water in air

\# CHASER on-line aerosol simulation (not used in CMIP5 simulations)

(7) Atmosphere $\Rightarrow$ Ocean

Eastward Wind (lowest layer)

Northward Wind (lowest layer)

Air Temperature (lowest layer)

Specific Humidity (lowest layer)

Air Pressure

Surface Air Pressure

Surface Height

Net Downward Shortwave Radiation at Sea Water Surface

Solar Zenith Angle

Mole Fraction of $\mathrm{CO}_{2}$ in Air

Henry constant (for CHASER)

precipitation flux: cumulus (for CHASER)

precipitation flux: Large Scale Condensation (for CHASER)

latitude

(8) Ocean $\Rightarrow$ Atmosphere

Albedo

Surface Temperature

Surface Upward $\mathrm{CO}_{2}$ Flux

Bulk Coefficient

Sea Ice Mass

deposition velocity for CHASER

biological emission flux (terpenes, isoprene) for CHASER

(9) Ocean $\Rightarrow$ Ocean biogeochemistry

Sea Water Potential Temperature

Net Downward Shortwave Radiation at Sea Water Surface

Solar Zenith Angle

Surface Upward $\mathrm{CO}_{2}$ Flux

Sea Surface Height Above Geoid

Dissolved Nitrate Concentration

Phytoplankton Carbon Concentration 
Table 1. Continued.

\begin{tabular}{l}
\hline Zooplankton Carbon Concentration \\
Detrital Organic Carbon Concentration \\
Calcite Concentration \\
Calcium \\
Dissolved Inorganic Carbon Concentration \\
Total Alkalinity \\
Sea Water Salinity \\
\hline (10) Ocean biogeochemistry $\Rightarrow$ Ocean \\
\hline Surface Aqueous Partial Pressure of $\mathrm{CO}_{2}$ \\
Sea Water CO 2 Solubility \\
\hline (11) Atmosphere $\Rightarrow$ Land (MATSIRO) \\
\hline Eastward Wind (lowest layer) \\
Northward Wind (lowest layer) \\
Air temperature (lowest layer) \\
Specific humidity (lowest layer) \\
Air pressure (Lowest layer/Surface) \\
Downward radiation fluxes (6 components: Visible/Near Infrared/Infrared, Direct/Diffuse) \\
Solar Zenith Angle (for parameterization of radiation transfer in canopy) \\
Mole Fraction of CO ${ }_{2}$ in Air (lowest layer) \\
Henry constant (from CHASER) \\
Precipitation (including snowfall, 2 types: cumulus/large-scale condensation) \\
Surface deposition of soil dust (from SPRINTARS) \\
Surface deposition of black carbon (from SPRINTARS) \\
\hline (12) Land (MATSIRO) -> Atmosphere \\
\hline Surface Upward Eastward Wind Stress \\
Surface Upward Northward Wind Stress \\
Surface Upward Sensible heat flux \\
Surface Upward Latent heat flux \\
Upward radiation fluxes (Short wave/Long wave) \\
Albedo (6 components: Visible/Near Infrared/Infrared, Direct/Diffuse) \\
Surface temperature \\
Evapotranspiration (6 components: Transpiration/Interception/Ground, Evaporation/Sublimation) \\
Snow sublimation \\
$10 \mathrm{~m}$ Wind (to SPRINTARS, CHASER) \\
2 m temperature (to SPRINTARS, CHASER) \\
$2 \mathrm{~m}$ Specific humidity (to SPRINTARS, CHASER) \\
Surface wetness (to SPRINTARS) \\
Snow water equivalent (to SPRINTARS) \\
Bulk coefficient for eddy transfer (to SPRINTARS) \\
Deposition fluxes of tracers (lowerst layer/surface) (to CHASER) \\
Emission (to CHASER) \\
(13) MATSIRO $\Rightarrow$ SEIB-DGVM \\
\hline
\end{tabular}

(13) MATSIRO $\Rightarrow$ SEIB-DGVM

Precipitation

Downward short wave radiation

Mole fraction of $\mathrm{CO}_{2}$ in air

$2 \mathrm{~m}$ temperature

Eastward $10 \mathrm{~m}$ wind speed

Northward $10 \mathrm{~m}$ wind speed

$2 \mathrm{~m}$ Specific humidity

Soil temperature

\begin{tabular}{l}
\hline (14) SEIB-DGVM $\Rightarrow$ MATSIRO \\
\hline Leaf Area Index \\
Atmosphere-Land carbon flux (Net carbon balance) (Through to Atmosphere) \\
\hline (15) MATSIRO -> Ocean \\
\hline River runoff
\end{tabular}


in the present study. Unlike other setups of the MIROCAGCM, MIROC-ESM has the fully resolved stratosphere and mesosphere (Watanabe et al., 2008a). The hybrid terrainfollowing (sigma) pressure vertical coordinate system is used, and there are 80 vertical layers between the surface and about $0.003 \mathrm{hPa}$. In order to obtain the spontaneously generated equatorial quasi-biennial oscillation (QBO), a fine vertical resolution of about $680 \mathrm{~m}$ is used in the lower stratosphere.

The MIROC-AGCM has a suite of physical parameterizations that are detailed in K-1 model developers (2004) and Nozawa et al. (2007). Watanabe et al. (2008a) describes the modifications and inclusions of physical parameterizations from MIROC-AGCM to MIROC-ESM that are crucial for the representation of the large-scale dynamical and thermal structures in the stratosphere and mesosphere. A brief summary of the physical parameterization is given in the following.

The radiative transfer scheme adopted in MIROC-ESM follows Sekiguchi and Nakajima (2008) and is an updated version of the $k$-distribution scheme used in the previous versions of MIROC-AGCM. Watanabe et al. (2008a) illustrated the improvements of the simulated thermal structure in MIROC-ESM-CHEM by replacing the old scheme with the new one. The present scheme considers 29 and $37 \mathrm{ab}-$ sorption bands in MIROC-ESM and MIROC-ESM-CHEM, respectively. The spectral resolution in visible and ultra violet regions is increased from 15 in MIROC-ESM to 23 in MIROC-ESM-CHEM, because detailed calculations are required for photolysis. Direct and indirect effects of aerosols are considered in the radiation scheme, which will be described in Sect. 2.1.2.

The cumulus parameterization is based on the scheme presented by Arakawa and Schubert (1974). A prognostic closure is used in the cumulus scheme, in which cloud base mass flux is treated as a prognostic variable. An empirical cumulus suppression condition is introduced (Emori et al., 2001), by which cumulus convection is suppressed when cloud mean ambient relative humidity is less than a critical value. This is a parameter by which the spatio-temporal distribution of the parameterized cumulus precipitation, and hence characteristics of vertically propagating atmospheric waves generated by cumulus convection, are strongly controlled. In the present setup of MIROC-ESM, a value of 0.7 is used for this parameter to generate moderate convective precipitation and a moderate wave momentum flux associated with the resolved atmospheric waves.

The large-scale (grid-scale) condensation is diagnosed based on the scheme of Le Treut and Li (1991) and a simple cloud microphysics scheme. In MIROC-ESM, the cloud phase (solid or liquid) is diagnosed according to the temperature, $T$ :

$$
\begin{aligned}
& \text { fliq }=\exp \left(-\left(\left(T_{\mathrm{s}}--T\right) / T_{\mathrm{f}}\right)^{2}\right) \quad\left(T>T_{\mathrm{m}}\right), \\
& \text { fliq }=0 \quad\left(T<T_{\mathrm{m}}\right),
\end{aligned}
$$

where fliq is the ratio of liquid cloud water to total cloud water, and $T_{\mathrm{m}}, T_{\mathrm{s}}$, and $T_{\mathrm{f}}$ are set to $235.15 \mathrm{~K}, 268.91 \mathrm{~K}$, and $12.0 \mathrm{~K}$, respectively.

The sub-grid vertical mixing of prognostic variables is calculated on the basis of the level 2 scheme of the turbulence closure model by Mellor and Yamada (1974, 1982). MIROC-ESM uses $\nabla^{6}$ horizontal hyper viscosity diffusion to suppress the effect of extra energies at the largest horizontal wave number. The horizontal diffusion is not applied to the tracers since the tracer advection scheme is separated from the spectral dynamical core of MIROC-AGCM. The efolding time for the smallest resolved wave is 0.5 days. In order to prevent extra wave reflection at the top boundary, a sponge layer is added to the top level, which causes the wave motions to be greatly dampened.

The effects of orographically and non-orographically generated subgrid-scale internal gravity waves are parameterized following McFarlane (1987) and Hines (1997), respectively (Watanabe et al., 2008a). As documented in Watanabe et al. (2008a) and Watanabe (2008), the present-day climatology of non-orographic gravity wave source spectra estimated using results of a gravity wave-resolving version of MIROCAGCM (Watanabe et al., 2008b) are launched at $70 \mathrm{hPa}$ in the extratropics of MIROC-ESM. The non-orographic gravity waves are mainly emitted from convection, jet-frontal systems, and adjustment processes, in the troposphere, propagating upward to the $70 \mathrm{hPa}$ level. In the tropics, an isotropic source of non-orographic gravity waves is launched at $650 \mathrm{hPa}$ in the present version. The strength of the tropical source is arbitrarily tuned so that the QBO with a realistic period of 27-28 months on average can be reproduced under present-day (2000s) conditions. As a consequence, the period of simulated QBO elongates with increasing GHG concentrations due to strengthening of the Brewer-Dobson circulation in the stratosphere (Watanabe and Kawatani, 2011).

\subsubsection{Aerosol module - SPRINTARS}

An aerosol module in MIROC, SPRINTARS, predicts mass mixing ratios of the main tropospheric aerosols: carbonaceous (BC and organic matter; $\mathrm{OM}$ ), sulfate, soil dust, and sea salt, and the precursor gases of sulfate, i.e. sulfur dioxide $\left(\mathrm{SO}_{2}\right)$ and DMS. The aerosol transport processes include emission, advection, diffusion, sulfur chemistry, wet deposition, dry deposition, and gravitational settling. Emissions of soil dust, sea salt, and DMS are calculated using the internal parameters of the model, and external emission inventories are used for the other aerosol sources. SPRINTARS is coupled with the radiation and cloud/precipitation schemes for calculating the direct, semi-direct, and indirect effects of aerosols. In the calculation of the direct effect, the refractive indices depending on wavelengths, size distributions, and hygroscopic growth are considered for each type of aerosol. The aerosol semi-direct effect is also included as a consequence of a link between the GCM and aerosol 
module. Number concentrations for cloud droplets and ice crystals are prognostic variables as well as their mass mixing ratios, and changes in their radii and precipitation rates are calculated for the indirect effect. More detailed descriptions of SPRINTARS can be found in Takemura et al. (2000) for the aerosol transport, Takemura et al. (2002) for the aerosol direct effect, and Takemura et al. (2005, 2009) for the aerosol indirect effect on water and ice clouds. Some improvements to each process are described in the later references.

\subsubsection{Chemistry module - CHASER}

Simulations of atmospheric chemistry in MIROC-ESMCHEM are based on the chemistry model CHASER (Sudo et al., 2002a, 2007) which has been developed mainly at Nagoya University in coorporation with the University of Tokyo, JAMSTEC, and NIES (Fig. 2). The CHASER model version used in MIROC-ESM-CHEM considers the detailed photochemistry in the troposphere and stratosphere by simulating tracer transport, wet and dry deposition, and emissions. The original version of CHASER (Sudo et al., 2002a) focused mainly on tropospheric chemistry, and has been extended to include the stratosphere by incorporating halogen chemistry and related processes. In its present configuration, the model considers the fundamental chemical cycle of $\mathrm{O}_{\mathrm{x}}-\mathrm{NO}_{\mathrm{x}}-\mathrm{HO}_{\mathrm{x}}-\mathrm{CH}_{4}-\mathrm{CO}$ with oxidation of VOCs and halogen chemistry calculating concentrations of 92 chemical species with 262 chemical reactions (58 photolytic, 183 kinetic, and 21 heterogeneous reactions). For VOCs, the model includes oxidation of ethane $\left(\mathrm{C}_{2} \mathrm{H}_{6}\right)$, ethene $\left(\mathrm{C}_{2} \mathrm{H}_{4}\right)$, propane $\left(\mathrm{C}_{3} \mathrm{H}_{8}\right)$, propene $\left(\mathrm{C}_{3} \mathrm{H}_{6}\right)$, butane $\left(\mathrm{C}_{4} \mathrm{H}_{10}\right)$, acetone, methanol, isoprene, and terpenes. The model adopts the condensed isoprene oxidation scheme of Pöschl et al. (2000) which is based on the Master Chemical Mechanism (MCM, Version 2.0) (Jenkin et al., 1997). Terpene oxidation is largely based on Brasseur et al. (1998). The model also includes detailed stratospheric chemistry, calculating $\mathrm{ClO}_{\mathrm{x}}$, $\mathrm{HCl}, \mathrm{HOCl}, \mathrm{BrO}_{\mathrm{x}}, \mathrm{HBr}, \mathrm{HOBr}, \mathrm{Cl}_{2}, \mathrm{Br}_{2}, \mathrm{BrCl}, \mathrm{ClONO}_{2}$, $\mathrm{BrONO}_{2}, \mathrm{CFCs}$, HFCs, and OCS. The formation of PSCs and associated heterogeneous reactions on their surfaces (13 reactions for halogen species and $\mathrm{N}_{2} \mathrm{O}_{5}$ ) are calculated based on the schemes adopted in the CCSR/NIES stratospheric chemistry model (Akiyoshi et al., 2004; Nagashima et al., 2001). The photolysis rates (J-values) are calculated on-line using temperature and radiation fluxes computed in the radiation component of the MIROC-AGCM (Sekiguchi and Nakajima, 2008) considering absorption and scattering by gases, aerosols, and clouds as well as the effect of surface albedo. In MIROC-ESM-CHEM, influences of short-wave radiative forcing associated with the solar cycle, volcanic eruptions, and subsequent changes in stratospheric ozone are also taken into account for the calculation of the photolysis rate. In the original MIROC-AGCM, the wavelength resolution for the radiation calculation is relatively coarse in the ultraviolet and the visible wavelength regions as in general GCMs.
Therefore, the wavelength resolution in these wavelength regions is improved for the photochemistry in CHASER (see Sect. 2.1.1). In addition, representative absorption crosssections and quantum yields for individual spectral bins are evaluated depending on the optical thickness computed in the radiation component. In a similar manner to Landgraf and Crutzen (1998), we optimized the averaging (weighting) function for each spectral bin differently for the troposphere and stratosphere. The simulated distributions of trace gases are generally well in line with the observations (Sudo et al., 2002b).

In the default configuration of the MIROC-ESM-CHEM model, sulfate formation from oxidation of $\mathrm{SO}_{2}$ and DMS is basically simulated in the SPRINTARS model component using concentrations of oxidants $\left(\mathrm{OH}, \mathrm{O}_{3}\right.$, and $\left.\mathrm{H}_{2} \mathrm{O}_{2}\right)$ calculated by the CHASER chemistry. Alternatively, the CHASER model component can simulate sulfate and nitrate aerosols on-line in cooperation with the aerosol thermodynamics model ISORROPIA (Nenes et al., 1998; Fountoukis et al., 2007) by considering the ammonia chemistry. It should be noted that sulfate simulation in CHASER considers neutralization of acidity of cloud water by ammonium and dust cations and its influences on liquid phase oxidation of S(IV) to form sulfate, but such processes are not included in the SPRINTARS sulfate simulation (which assumes a constant $\mathrm{pH}$ value for cloud water). The latest version of CHASER also includes chemical formation of secondary organic aerosol (SOA) from oxidation of VOCs (isoprene, terpenes, and aromatics) with a "two product" scheme based on Odum et al. (1996). However, our present experiments for the CMIP5 and related projects do not use this on-line SOA simulation mainly because it is yet to be adequately validated.

The spatial and temporal resolutions for the chemistry and aerosol calculations are linked to the main dynamical and physical cores of the model (MIROC-AGCM), and grid/subgrid scale tracer transport is simulated in the framework of the GCM.

For the CMIP5 related experiments, surface and aircraft emissions of $\mathrm{BC} / \mathrm{OC}$ and precursor gases $\left(\mathrm{NO}_{\mathrm{x}}, \mathrm{CO}, \mathrm{VOCs}\right.$, and $\mathrm{SO}_{2}$ ) are specified from the RCP database (Lamarque et al., 2010, etc.). Lightning NOx emission, calculated in the convection scheme of the MIROC-AGCM, is changeable from year to year responding to the interannual variability and climatic trends. Although MIROC-ESMCHEM includes the land surface model MATSIRO and the land ecosystem model SEIB-DGVM, biogenic emissions of VOCs, such as isoprene or terpenes, are not curently linked to the vegetation processes in these models.

\subsection{Ocean and sea-ice model with biogeochemistry}

The ocean component of MIROC-ESM is developed at CCSR, University of Tokyo, and is called COCO, the acronym of CCSR Ocean COmponent model. The COCO 


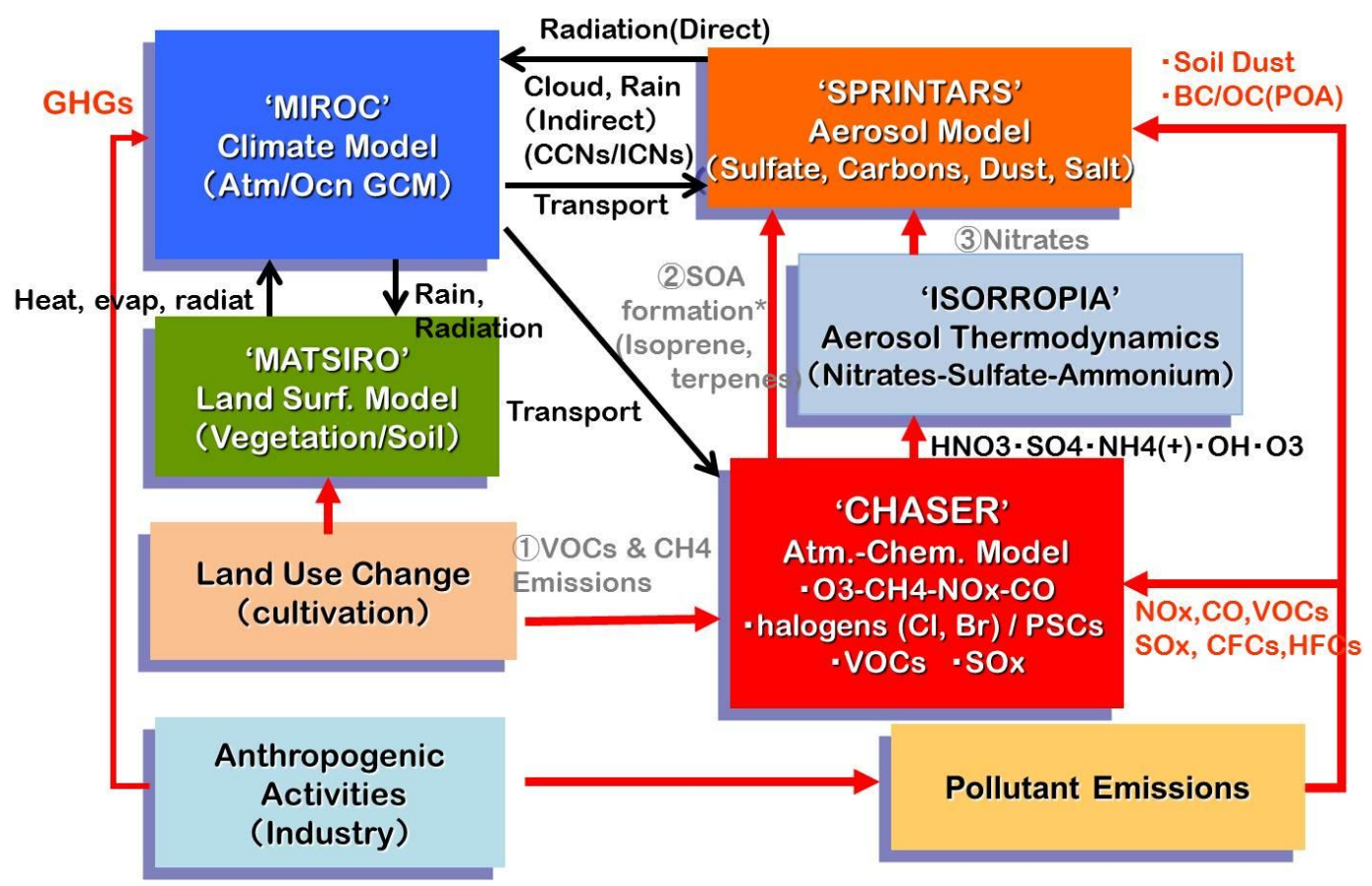

Fig. 2. Coupling of chemistry and aerosol calculations (based on the CHASER and SPRINTARS models) in the MIROC-ESM-CHEM modeling framework. Note that SOA production from VOCs and nitrate aerosol $\left(\mathrm{NO}_{3}^{-}\right)$are considered in the CHASER component in cooperation with the aerosol thermodynamics module ISORROPIA, but are not included in the simulation for the CMIP5 and other related experiments.

solves the primitive equations under hydrostatic and Boussinesq approximations with an explicit free surface. The surface mixed layer parameterization is based on Noh and Kim's turbulence closure scheme (Noh and Kim, 1999), a derivative of Mellor and Yamada level 2.5 (Mellor and Yamada, 1982). The sea-ice is based on a two-category thickness representation, zero-layer thermodynamics (Semtner, 1976), and dynamics with elastic-viscous-plastic rheology (Hunke and Dukowicz, 1997).

The horizontal resolution for COCO is finer than for the atmospheric model. The longitudinal grid spacing is about 1.4 degrees, while the latitudinal grid intervals gradually vary from 0.5 degrees at the equator to 1.7 degrees near the North/South Pole. The vertical coordinate is a hybrid of sigma- $z$, resolving 44 levels in total: 8 sigma-layers near the surface, and $35 z$-layers at depth, plus one bottom layer for the boundary parameterization (K-1 model developers, 2004).

A simple biogeochemical process is employed to simulate the ocean ecosystem. A type of Nutrient-PhytoplanktonZooplankton-Detritus model (NPZD, Oschlies, 2001) is sufficient to resolve the seasonal variation of oceanic biological activities at a basin-wide scale (Kawamiya et al., 2000). The biological primary production and NPZD variables are computed above the euphotic layer, in a nitrogen-base. A constant Redfield ratio $(\mathrm{C} / \mathrm{N}=6.625)$ is used to estimate the carbon and calcium flow. The sea-air $\mathrm{CO}_{2}$ flux is calculated by multiplying the difference of ocean-atmosphere $\mathrm{CO}_{2}$ partial pressures by the ocean gas solubility.

\subsection{Land surface models}

\subsubsection{Physical land component - MATSIRO}

MIROC-ESM includes a land surface model: Minimal Advanced Treatments of Surface Interaction and RunOff (MATSIRO; Takata et al., 2003), coupled to a river routing model, TRIP (Oki and Sud, 1998), for calculating river discharge. In MATSIRO, the heat and water exchanges between the land and atmosphere are calculated, as are the thermal and hydrological conditions in the soil. The model consists of a single layer canopy, three layers of snow, and six layers of soil to a depth of $14 \mathrm{~m}$.

The aging effect on snow albedo (Yang et al., 1997) has been applied to MATSIRO. The effects of dirt in snow had been considered as a constant after Yang et al. (1997), but was modified to vary in accordance with the dirt concentration at the snow surface to mimic the observed relation between snow albedo and dirt concentration (Aoki et al., 2006). The dirt concentration in snow is calculated from the deposition fluxes of dust and soot calculated in the aerosol module, SPRINTARS (Sect. 2.1.2). Since the absorption coefficients of dust and soot are very different, the relative strength of 
their absorption ( 0.012 for soil dust and 0.988 for black carbon) are weighted to the deposition fluxes to obtain a radiatively effective amount of dirt in snow.

The surface albedo of an ice sheet had been assumed to be constant, but has been modified to consider the effects of melt water on the surface (Bougamont et al., 2005). Here, the ice sheet albedo is a function of the water content above the ice for visible and near-infrared radiation, and is a fixed value of 0.05 for the infrared band.

\subsubsection{Land ecosystem model - SEIB-DGVM}

The process-based terrestrial ecosystem model SEIB-DGVM (Spatially Explicit Individual-Based Dynamic Global Vegetation Model; Sato et al., 2007; Ise et al., 2009) was coupled to MIROC-ESM to simulate global vegetation dynamics and terrestrial carbon cycling. Under global climate change, terrestrial ecosystems will be affected by aspects including shifts in vegetation types, changes in living biomass, alterations of vegetation structure and energy balance, and accumulation and decomposition of soil organic carbon. These changes will in turn influence the climate, thereby forming a terrestrial-atmosphere feedback. In order to appropriately reproduce these terrestrial ecological processes, SEIB-DGVM adopts an individual-based simulation scheme that explicitly captures light competition among trees, while other terrestrial ecosystem models (e.g. Sitch et al., 2003) rely heavily on parameterization for plant competition. Incorporating ecological realities of competition for light is fundamentally important to strengthen DGVM predictions (Purves and Pacala, 2008). SEIB-DGVM has been validated in various regions with different biomes (Ise and Sato, 2008; Sato, 2009; Sato et al., 2010). In this model, the ecological processes - ecophysiology, population, community, and ecosystem dynamics are simulated in an integrated manner.

In SEIB-DGVM, vegetation is classified into 13 plant functional types (PFTs), consisting of 11 tree PFTs and 2 grass PFTs. Each PFT has different ecophysiological parameters such as maximum photosynthetic rates, optimal temperatures for photosynthesis, and minimum temperatures for frost-related mortality. Allometry relationships and carbon allocation patterns also differ, resulting in differential growth patterns and competition among PFTs under the environmental conditions in each grid cell. Photosynthesis is calculated daily as a function of air temperature, photosynthetically active radiation, and atmospheric $\mathrm{CO}_{2}$ concentration, and modified by air humidity through stomatal control and soil moisture availability. Plant respiration is controlled by the volume of plant tissues (i.e. leaves, stems, and root), growth rates of each tissue, and air temperature with a $Q_{10}$ function. Population dynamics (establishment, growth, and mortality) and community dynamics (competition and succession) are then simulated from the daily gain from photosynthesis by each tree.
Dynamics of soil organic carbon is determined by inputs (turnover of plant tissues and mortality) and the output (decomposition by heterotrophic respiration). Heterotrophic respiration responds linearly to the soil water content and exponentially to the soil temperature via an Arrhenius-type equation. SEIB-DGVM in MIROC-ESM contains two soil organic carbon pools (fast- and slow-decomposing) based on the Roth-C scheme (Coleman and Jenkinson, 1999). The ecosystem carbon balance is then calculated by adding changes in living biomass and soil organic carbon.

In order to represent the effects of anthropogenic land use change, SEIB-DGVM incorporates land use datasets of RCPs scenarios (Hurtt et al., 2009) for the period 1500-2100. The spatial resolution of the datasets is converted to T42 and land use types are summarized into five categories: primary vegetation, secondary vegetation, pasture, cropland, and urban area. Transitions are reproduced by a dataset of fractional changes of land use area in each grid of MIROC-ESM and computed using an annual time step. The secondary vegetation is formed as a result of logging or burning of primary forests or abandonment of agricultural land. Regrowth of forest PFTs is then simulated by the individual-based forest dynamics scheme. Carbon in harvested biomass is transferred into carbon pools of linear decay (with turnover times of 1 , 10 , and $100 \mathrm{yr}$ ) according to the Grand Slam Protocol described in Houghton et al. (1983). We simulate the ecosystem dynamics of agricultural land using the processes for natural grassland, but the biomass of cropland is harvested annually and partly transferred into the grand slam carbon pools. The anthropogenic land use changes alter the vegetation structure and carbon cycle in terrestrial ecosystems, and resultant changes of land surface conditions and atmospheric $\mathrm{CO}_{2}$ will affect the climate through biophysical/biogeochemical processes.

\section{Spin-up and experimental designs}

\subsection{Spin-up and initial condition}

Figure 3 schematically illustrates the spin-up procedures of MIROC-ESM. The terrestrial and ocean carbon cycles require a long time to reach equilibrium compared to physical climate systems. In our approach, the terrestrial carbon cycle component including the vegetation dynamics (SEIBDGVM) and the ocean carbon cycle component embedded in the ocean GCM were separately spun-up for 2000 and $1245 \mathrm{yr}$, respectively (Fig. 3a). In these first off-line spinup runs, surface physical quantities such as winds, temperature, moisture, precipitation, and radiation flux, which are the year-round daily climatology of a pre-industrial run of MIROC, were recursively adapted to each model. Next, we inputted the resultant equilibrated carbon cycle data into a low-top version of MIROC-ESM, in which the L80-AGCM is replaced by a L20-AGCM for computational efficiency, as 


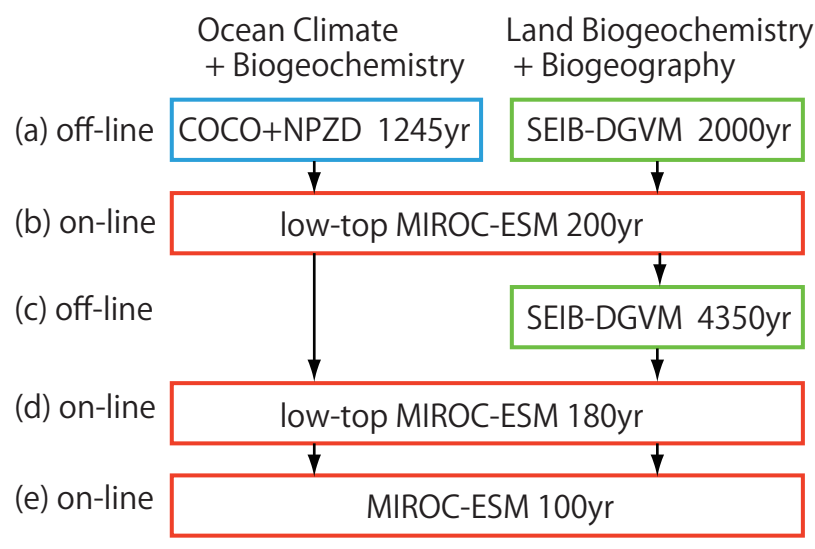

Fig. 3. Spin-up procedures of MIROC-ESM.

initial conditions, and the on-line terrestrial and ocean carbon cycles were integrated for $200 \mathrm{yr}$ (Fig. 3b). The resultant terrestrial carbon cycle state was again input into the off-line SEIB-DGVM, which was integrated for $4350 \mathrm{yr}$ to adapt to the land-use corresponding to 1850 (Fig. 3c). Using the terrestrial carbon cycle data, the second on-line spin-up was conducted using the low-top MIROC-ESM for $180 \mathrm{yr}$ (Fig. 3d), from which the final states of carbon cycle are used as the initial conditions for the final on-line spin-up of MIROC-ESM with the L80-AGCM (Fig. 3e).

In the course of the spin-up runs, we monitored representative states and fluxes in the physical climate and carbon cycle components, for example, surface air temperatures, radiation fluxes at the top of atmosphere, strength of the thermohaline circulation, sea-ice extent, soil and vegetation carbon storage, land and ocean carbon uptakes, and so many. Each of the spin-up runs was continued until linear trends of those quantities in the last $50 \mathrm{yr}$ became insignificant. After the spin-up had finished, we conducted the pre-industrial control run of MIROC-ESM for $530 \mathrm{yr}$, and the first day of the 20th year of the control run was used as the initial condition of the chemistry coupled spin-up of MIROC-ESM-CHEM, which is described in the next paragraph.

The atmospheric chemistry component (CHASER) of MIROC-ESM-CHEM was spun-up separately from the carbon cycles because the atmospheric chemistry does not need thousands of years to reach equilibrium. Some chemical species important in the stratosphere required a few tens of years to reach equilibrium if the surface emission of source gases was substantially changed. Since we had only run the current version of CHASER under present-day conditions before CMIP5, we first needed to prepare appropriate initial conditions for 1850 utilizing the existing presentday dataset: (1) concentrations of halogen compounds such as halocarbons, inorganic chlorine and bromine were set to zero, (2) concentrations of the nitrogen family such as nitrogen dioxide was scaled on the basis of present-day values with reference to the surface concentration of nitrous oxide, and (3) concentration of methane and moisture were scaled with reference to the surface concentration of methane. After a spin-up of about $15 \mathrm{yr}$, the concentrations of all chemical compounds in the troposphere and stratosphere reached equilibrium. The chemistry spin-up run was continued for $28 \mathrm{yr}$, and the final states of the chemistry tracers were added to the initial condition of the carbon cycles described in the previous paragraph.

Finally, a fully-coupled carbon cycles-chemistry spin-up run was performed for $4 \mathrm{yr}$ to derive the initial condition of the historical simulation, whose results are described in Sect. 4. This short final spin-up run was possible because: (1) the pre-industrial mean climate of MIROC-ESM that is used for the carbon cycle spin-up and of MIROC-ESMCHEM was actually similar to each other, because ozone distribution in these models is similar. (2) The present version of MIROC-ESM-CHEM does not include any direct coupling between the carbon cycles and atmospheric chemistry. The atmospheric chemistry indirectly affects ecosystems through chemistry-climate interactions. At least, we did not find any apparent changes in ecosystems before and after the chemistry coupling.

\subsection{Experimental designs}

The historical simulation was performed for the period from 1850 to 2005 using a set of external forcings recommended by the CMIP5 project. Spectral changes in solar irradiance are considered according to Lean et al. (2005). Historical changes in optical thickness of volcanic stratospheric aerosols are given by Sato et al. (1993) and subsequent updates (http://data.giss.nasa.gov/modelforce/strataer/). Unlike our previous simulations, the temporal evolution of the optical thickness in latitude-altitude cross section is considered. From 1998, the optical thickness of volcanic stratospheric aerosols is exponentially reduced with one year relaxation time. In CMIP5 simulations, CHASER and SPRINTARS do not calculate stratospheric background aerosols made from carbonyl sulfide. The optical thickness of volcanic stratospheric aerosols does include the stratospheric background aerosols, and we use it in radiation calculations and heterogeneous chemistry calculations as the optical thickness per unit altitude can be converted into surface area density of aerosols. Atmospheric concentrations of well-mixed greenhouse gases are provided by Meinshausen et al. (2011). Surface emissions of tropospheric aerosols and ozone precursors are provided by Lamarque et al. (2010).

To appropriately incorporate the effects of anthropogenic land use, the harmonized land-use dataset (Hurtt et al., 2009) was implemented in the SEIB-DGVM. The harmonized land use dataset provided global land use type transitions among five types (primary vegetation, secondary vegetation, cropland, pasture, and urban area) in fractions annually at a resolution of 0.5 degrees and was prepared by integration 
of four RCP socioeconomic studies (IMAGE, MINICAM, AIM, and MESSAGE) and historical data (1500-2005). The original harmonized land-use data were converted to T42 to fit the spatial resolution of this study by taking weighted means. The quality of the conversion was checked graphically. Implementation of RCPs in SEIB-DGVM is described in Sect. 2.3.2.

\section{Results of historical simulation}

\subsection{Transient variations}

Temporal variations of global and annual mean surface air temperature (SAT) are shown in Fig. 4 for the MIROC-ESMCHEM simulation as well as for the observations (Brohan et al., 2006). The MIROC-ESM-CHEM simulation well captures the observed multi-decadal variations throughout the whole simulation period, although the simulated SAT is about $0.2 \sim 0.3 \mathrm{~K}$ cooler than observations since the Pinatubo eruption. The simulated SAT increase in the first and the second half of the 20th century is about 0.8 and $1.0 \mathrm{~K}$ century $^{-1}$ respectively, which is slightly less than that in the observations. These global annual mean SAT trends are similar to those of our previous simulations (Nozawa et al., 2007), although we use different forcing datasets than previously.

Figure 5 shows the geographical distributions of linear SAT trends for the first and second half of the 20th century. For the first half of the 20th century (Fig. 5a and b), the simulated SAT trends are about $1 / 2$ or smaller than observations over the ocean. The simulated SAT trends are positive over Eurasia despite the observed SAT trends are generally negative. For the second half of the 20th century (Fig. 5c and d), on the other hand, the overall SAT trend for the MIROC-ESM-CHEM simulation shows a realistic geographical pattern, as compared to the observed one: the simulated SAT trend pattern over the northern Pacific is very similar to that in observations, although the simulated trends over the Southern Hemisphere are about $1 \mathrm{~K}$ century $^{-1}$ smaller than those in observations.

\subsection{Climatology in the late 20th century}

Figure $6 \mathrm{a}$ and $\mathrm{b}$ shows geographical distributions of SAT averaged for the 1961-1990 periods for the MIROC-ESMCHEM simulation and its biases against observational dataset (Jones et al., 1999), respectively. Overall, MIROCESM-CHEM SAT distributions are realistic but their differences from observations show systematic biases: the simulated SAT is warmer in the mid and high latitudes of the Northern Hemisphere and over Antarctica. On the other hand, the simulated SAT is about $1 \sim 2 \mathrm{~K}$ cooler in the tropics and in the mid latitudes of the Southern Hemisphere.

The MIROC-ESM-CHEM shows a realistic distribution of annual mean precipitation for the 1981-2000 period (Fig. 6c). However, there are some differences compared

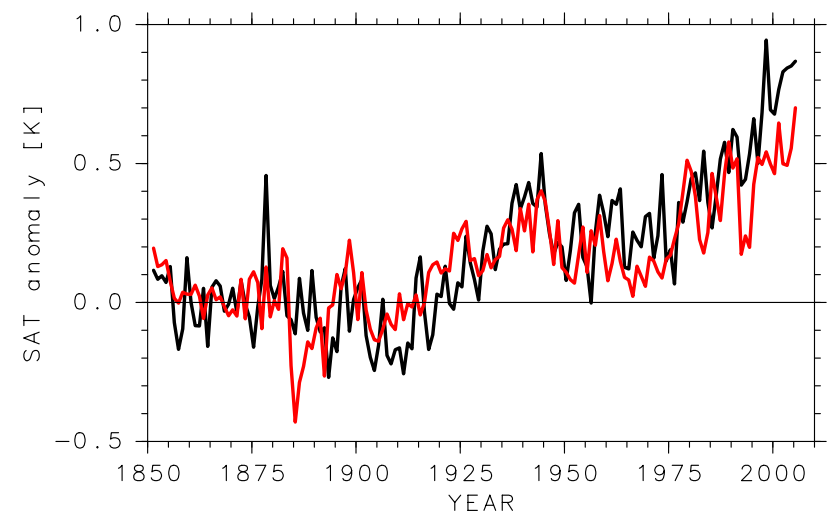

Fig. 4. Temporal variations of global annual mean surface air temperature (SAT). Anomalies from the 1851-1900 mean for the observations (Brohan et al., 2006; black line) and the MIROC-ESMCHEM simulation (red line). In calculating the global annual mean SAT, modeled data are projected onto the same resolution as the observations, discarding simulated data at grid points where there was missing observational data. At each location, more than two months of data were required to calculate the seasonal mean value, and all four seasons of data were required to calculate the annual mean value.

with the GPCP observational dataset (Adler et al., 2003) (Fig. 6d): the precipitation is underestimated along the South Pacific convergence zone (SPCZ), over the eastern side of the Maritime Continent, and over Central America, whereas it is overestimated over the Maritime Continent, the northwestern Indian Ocean, and the western side of South America. These shortcomings are similar to those in our previous model (MIROC3.2) because these two models have almost the same atmospheric physics components.

There is significant interest in how many years the Arctic and Antarctic sea-ice can last in a warming globe. Supposing a slightly warming ocean, both the sea-ice extent and the surface albedo would decrease and more solar radiation would be absorbed by the ocean, and hence initial warming is accelerated. Therefore, Arctic and Antarctic sea-ice are very sensitive in a changing climate and can provide a good benchmark for a climate model.

Figure 7 compares the sea-ice concentration between the reanalysis (Reynolds et al., 2002) and simulation by seasons and hemispheres. MIROC-ESM-CHEM reasonably simulates the sea-ice seasonality in both hemispheres. The sea-ice distribution is similar between the reanalysis and simulation. During the boreal summer (JJA), the Arctic Ocean has less sea-ice and the Southern Ocean has more sea-ice compared with the other seasons, and vice versa for the boreal winter (DJF).

However, some unrealistic features can be found in the simulation, especially over shallow oceans. Hudson Bay, for example, has thin sea-ice during the boreal summer in the reanalysis while no sea-ice is formed in the simulation. The 
(a)

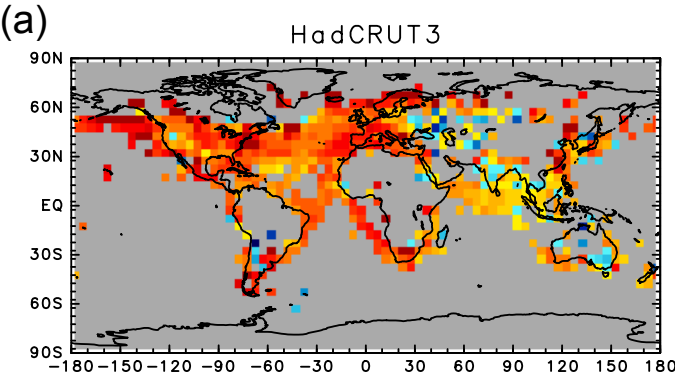

(b)

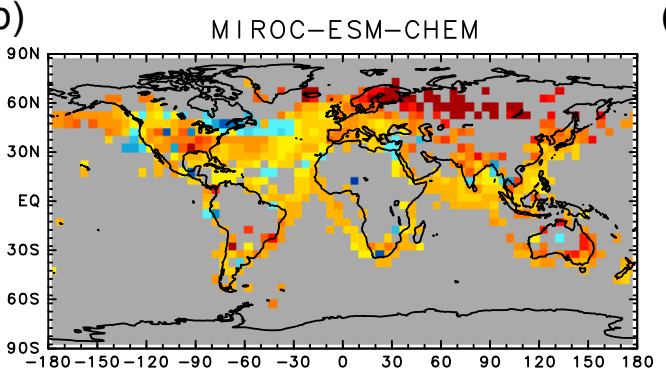

(c)

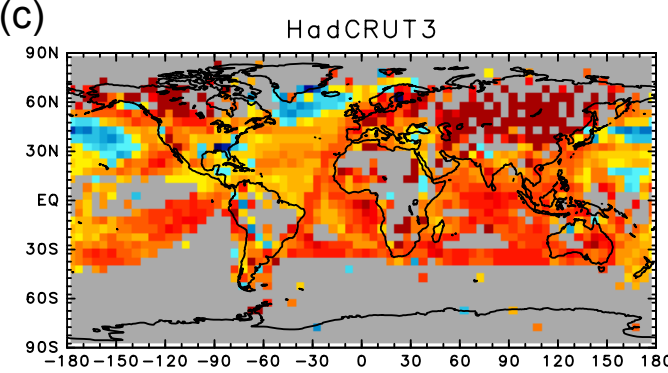

(d)
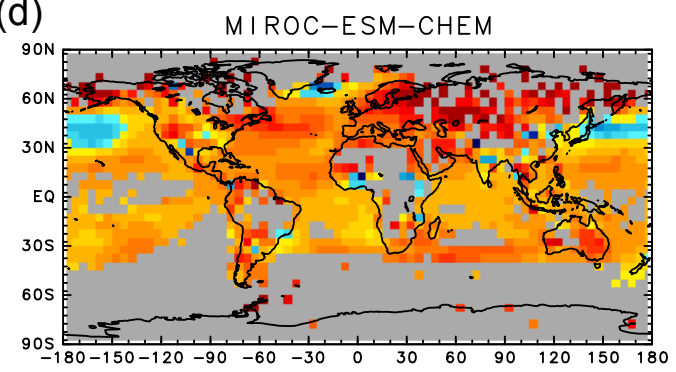

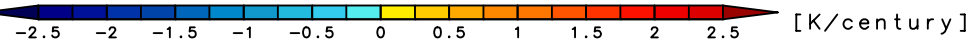

Fig. 5. Geographical distributions of linear surface air temperature trends $\left(K_{\text {century }}{ }^{-1}\right)$ in the (a, b) first and (c, d) second half of the 20 th century for the (a, c) observations (Brohan et al., 2006) and (b, d) the MIROC-ESM-CHEM simulation. Trends were calculated from annual mean values only for those grid points where the annual data is available in at least $2 / 3$ of the $50 \mathrm{yr}$ and distributed in time without significant bias.

southwestern Okhotskoe Sea and northern Barrentsovo Sea also have less sea-ice during the boreal winter in the simulation. Therefore, MIROC-ESM-CHEM underestimates a small amount of sea-ice over shallow oceans and such sea-ice may have disappeared by the 1990s, a bit earlier than in the observations, but the model adequately resolves most other sea-ice, which has more importance in a large-scale climate simulation.

The annual mean shortwave (SW) and longwave (LW) radiation at the top of the atmosphere (TOA), and their cloud radiative forcing (CRF) are shown in Figs. 8 and 9. The observational dataset from the Earth Radiation Budget Experiment (ERBE), Earth Radiant Fluxes and Albedo for Month S-9 for the period 1986 to 1990 (Barkstrom et al., 1989) is used for comparison with the model simulation. As shown in Fig. 8, negative bias in SW radiation (the model has too much reflection) and CRF can be seen in the central Pacific, western Atlantic, and Indian Ocean, and positive bias is seen in the eastern Pacific and Atlantic. These features are similar to the bias of low-level cloud albedo in Fig. 12 of Yokohata et al. (2010), and thus these biases are likely caused by the model feature of low-level cloud.

As for LW radiation, the bias is relatively small compared to that in SW radiation. A positive bias in LW radiation and LW CRF can be seen over the intertropical convergence zone (ITCZ) in the equatorial Pacific. Since this feature is similar to that of the precipitation bias shown in Fig. 6d, this positive bias in LW radiation is likely caused by a problem with the model precipitation or convection. Similarly, the negative bias in the LW radiation and LW CRF over the SPCZ may be related to the negative precipitation bias there (Fig. 6d).

The meridional cross sections of simulated zonal mean temperatures, specific humidity, and relative humidity are shown in Fig. 10, along with those biases against ERA-40 (Uppala et al., 2005). A cold bias is seen near the surface except in the Arctic. This is consistent with that in SAT (Fig. 6b). At higher altitudes, a cold bias is seen in the middle troposphere between $40^{\circ} \mathrm{N}$ and $50^{\circ} \mathrm{S}$, and a larger cold bias is seen in the extratropical upper troposphere and lower stratosphere.

A large negative (dry) bias is seen in the lower troposphere, especially at latitudes lower than 30 degrees. Reasons for the dry bias in these regions are related to the cold bias near the surface (Fig. 10b) and the dry bias in the relative humidity centered around $850 \mathrm{hPa}$ (Fig. 10d). In the region where the dry bias in relative humidity is maximal, the dry bias in specific humidity is also maximal. In the upper troposphere and lower stratosphere, a large positive (wet) bias in relative humidity is seen. This bias could cause the negative temperature bias (Fig. 10b) owing to an increase in LW emission to outer space.

The meridional cross sections of simulated zonal mean eastward winds and temperatures are shown in Fig. 11, along 


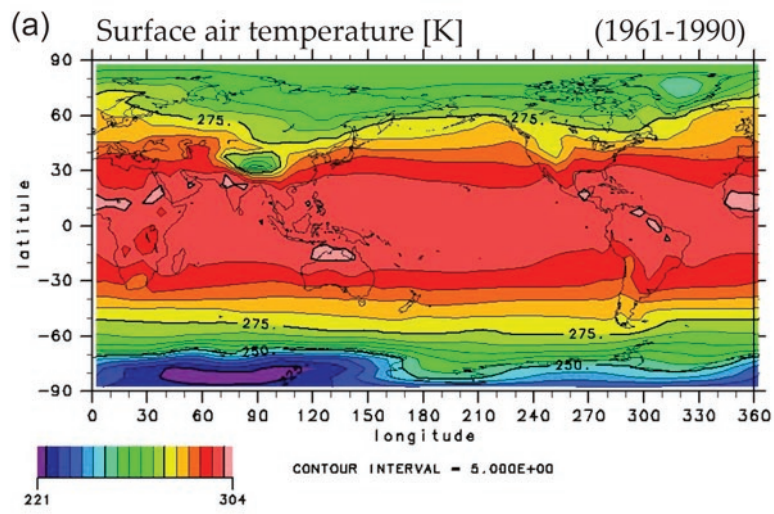

(c) Precipitation $\left[\mathrm{mmd}^{-1}\right]$

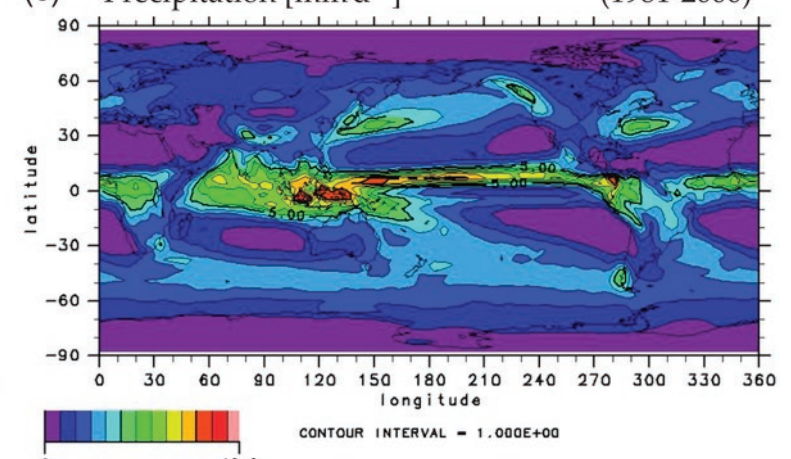

(d) (b) Surface air temperature bias $[\mathrm{K}]$

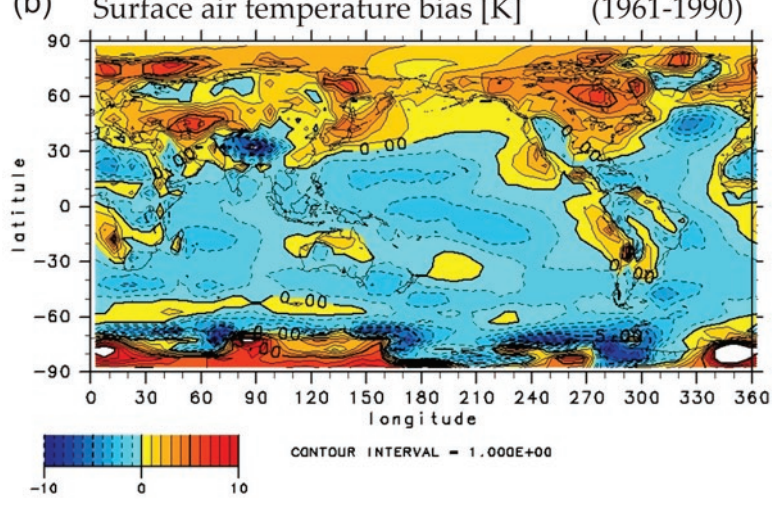

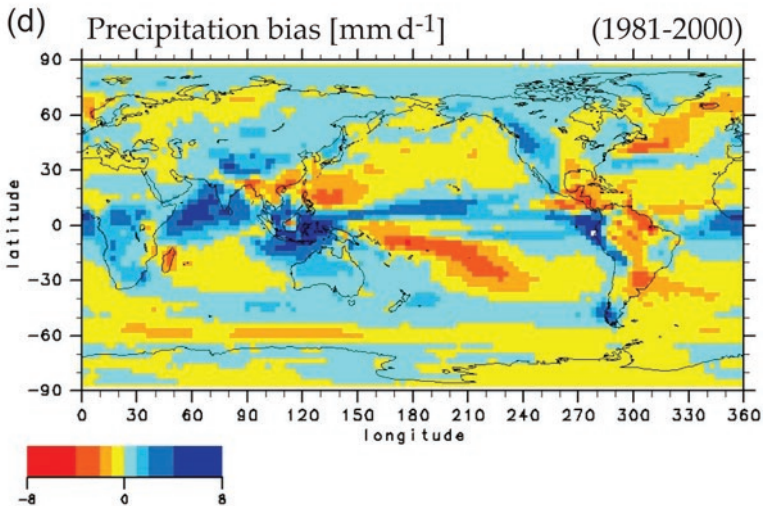

Fig. 6. (a) Annual mean climatology of surface air temperature (SAT) for the 1961-1990 period for the MIROC-ESM-CHEM simulations and (b) biases in the annual mean SAT climatology against the observational dataset (Jones et al., 1999). (c) Annual mean climatology of precipitation for the 1981-2000 period for the MIROC-ESM-CHEM simulations and (d) biases in the annual mean precipitation climatology against the GPCP observational dataset (Adler et al., 2003).

with those for ERA-40 (below $1 \mathrm{hPa}$ ) and the 1986 Committee on Space Research (COSPAR) International Reference Atmosphere (CIRA) data (above $1 \mathrm{hPa}$ ) (Fleming et al., 1990). The model qualitatively reproduces the observed meridional structure of the zonal mean winds and temperatures in each month (January, April, July, and October). Relatively large discrepancies between the model and observations are found in the winter hemisphere high latitudes. More frequent occurrence of stratospheric sudden warming than that in the observations in the 1990s results in weak winds in the northern winter upper stratosphere and mesosphere (Fig. 11a). Less gravity wave drag owing to a lack of lateral propagation in gravity wave drag parameterizations causes strong winds in the southern winter upper stratosphere and mesosphere (Fig. 11e, see Watanabe, 2008).

Figure 12 compares time-height cross-sections for the reanalysis (ERA-40) and simulated equatorial eastward winds. They both show alternation of downward propagating eastward and westward wind shear zones, known as the equatorial QBO. The mean periods of the observed and simulated QBO are similar to each other, i.e. approximately 28 months, while the simulated QBO behavior is somewhat regular compared to the reanalysis. This might be due to the constant gravity wave source specified in the tropics (Sect. 2.1.1). Otherwise, it could be attributed to less variability of resolved wave forcing and/or of the equatorial mean upward motions. The QBO in MIROC-ESM will be detailed in a forthcoming paper (Watanabe and Kawatani, 2011).

\subsection{Aerosols}

Significant changes in atmospheric aerosol loading from preindustrial times to the present result from industrial activities and biomass burning (Fig. 13). BC, OM, and sulfate from anthropogenic sources are emitted from East and South Asia, North America, and Europe and then transported to the outflow regions. They also originate from biomass burning caused by deforestation in Southeast Asia, central and southern Africa, and the Amazon. Figure 14 shows the time evolution of the global mean increasing rate of mass column loading for each aerosol component. BC and sulfate gradually increased after the Industrial Revolution to the first half of the 20th century mainly due to consumption of fossil fuel, and then accelerated after 1950s along with OM due 

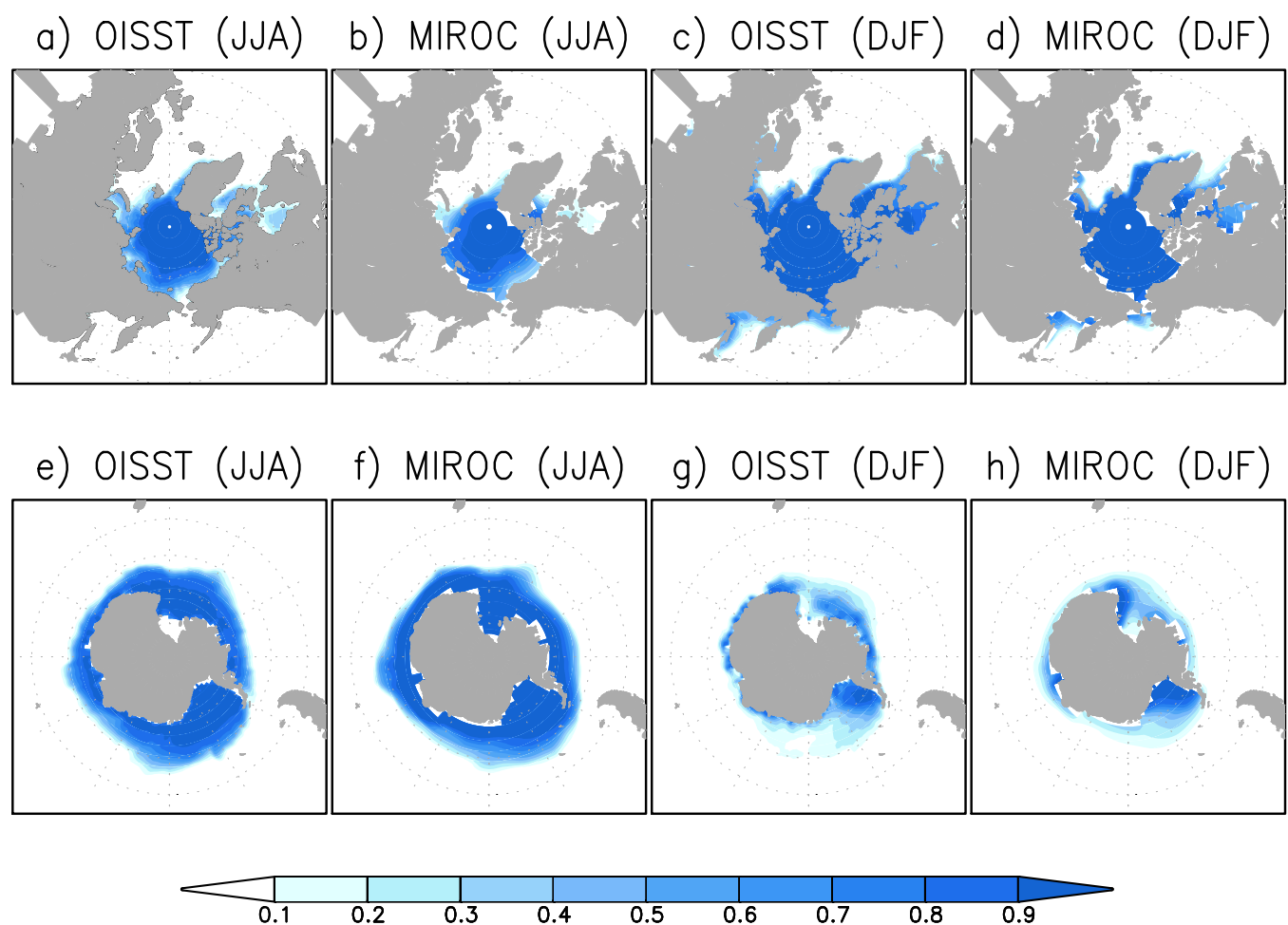

Fig. 7. Seasonal climatology of Arctic and Antarctic sea-ice concentration in the 1990s: for the boreal (JJA) and austral (DJF) summer, and the reanalysis (OISST) and simulation (MIROC-ESM-CHEM).

to rapid industrialization and deforestation. Global mean aerosol mass in the atmosphere at the end of the 20th century is about three times and twice as large as that in 1850 for BC and sulfate, respectively. Atmospheric dust slightly increased in the 20th century relative to the previous century. Anthropogenic aerosols from urban areas in the mid-latitudes of the Northern Hemisphere concentrate in the boundary layer, while biomass burning aerosols from tropical and subtropical regions are injected to higher altitudes due to convection and fire heat (Fig. 15). Figure 16 shows the direct radiative forcing at the tropopause due to anthropogenic aerosols under all-sky condition, which have strong negative values over industrialized and biomass burning regions. The radiative forcings of the direct and indirect effects due to anthropogenic aerosols are $-0.2 \mathrm{~W} \mathrm{~m}^{-2}$ and $-0.9 \mathrm{~W} \mathrm{~m}^{-2}$ for the global mean, respectively.

\subsection{Atmospheric chemistry}

Figure 17 displays the temporal evolution of the global mean ozone column reproduced by our past simulation with MIROC-ESM-CHEM using the RCP dataset for CMIP5. The total ozone column rapidly decreases after 1980 in response to the increased halogen loading, exhibiting the large influence of volcanic eruptions in 1980s and 90s. The decreasing trend of total ozone in 1980s, however, appears to be significantly underestimated by the model in view of the long-term trend in stratospheric ozone observed during this time period (about $-1 \% \mathrm{yr}^{-1}$ ) (e.g. World Meteorological Organization (WMO), 2007). In comparison with the total ozone measurements by the total ozone mapping spectrometer (TOMS), we found an overestimation (5-10\%) by the model in the low to midlatitudes through a year with a less overestimation $(<5 \%)$ in the northern high latitudes in winter to spring. The column ozone amount in the Antarctic ozone hole season is also overestimated by about $10 \%$. The model clearly simulates impacts of the 11-yr solar cycle on total ozone. In the troposphere, the model calculates a large increase of ozone from $24 \mathrm{DU}$ in 1850 to $33 \mathrm{DU}$ in 2000 due to enhanced emissions of precursors. This increasing ozone trend in the troposphere appears to be contributing to the positive trend of total ozone in the period before 1980 . The model may overestimate present-day tropospheric ozone abundance in comparison with the global mean ozone derived by the global ozone monitoring experiment (GOME) satellite measurements (Liu et al., 2005, 2006). Our estimated radiative forcing of tropospheric ozone $\left(0.41 \mathrm{~W} \mathrm{~m}^{-2}\right)$ is, however, in good agreement with the range suggested by IPCC (2007): +0.25 to $+0.65 \mathrm{~W} \mathrm{~m}^{-2}$ as the 5 to $95 \%$ confidence interval of the model ensemble including 9 previously published studies (Mickley et al., 2001, 2004; Shindell et al., 2003, 2005; etc.) and the 10 models of the ACCENT 
(a) SW Net

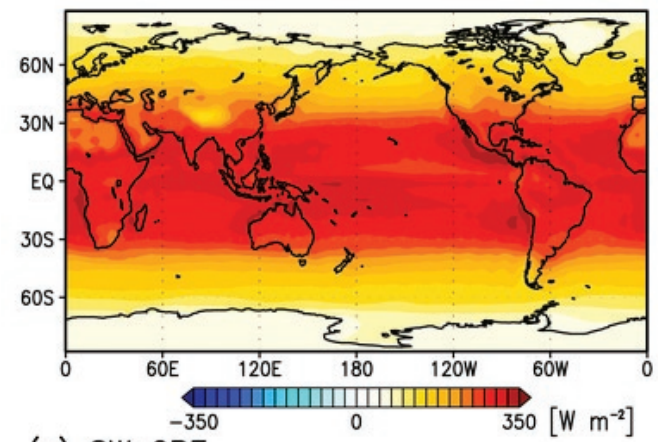

(c) SW CRF

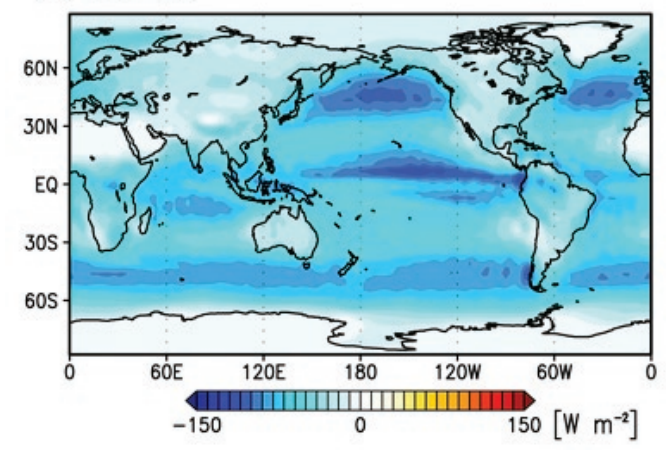

(b) SW Net, Bias

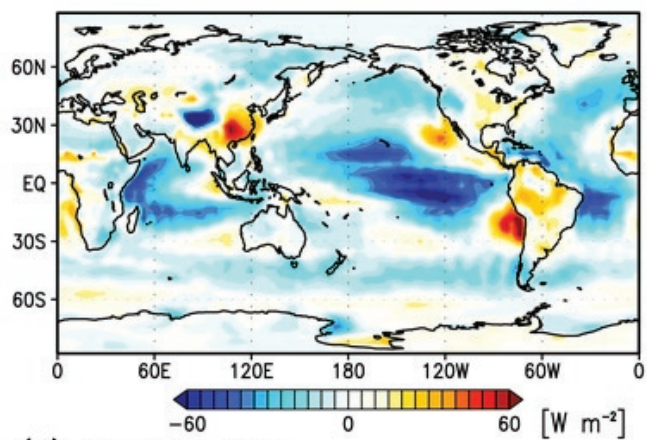

(d) SW CRF, Bias

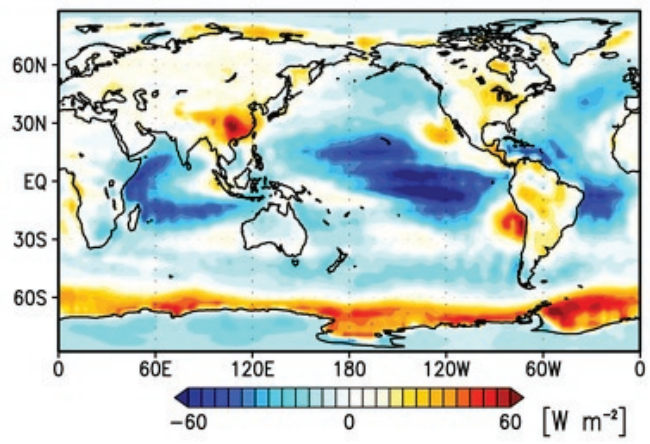

Fig. 8. Annual mean net downward (a, b) shortwave (SW) radiation at the top of the atmosphere (TOA), and (c, d) SW cloud radiative forcing (CRF) at the TOA. Results of the model simulation are shown in (a, c), and the model bias against ERBE observations (Barkstrom et al., 1989) is shown in (b, d) (see text).

experiment (Gauss et al., 2006). The spatial and seasonal distributions of tropospheric ozone calculated by the model are well consistent with the GOME observations (Fig. 18). Both the model and observation show large ozone increases in the northern mid-latitudes in spring (MAM) due to enhanced chemical production of ozone and downward transport of stratospheric ozone. In summer in the Northern Hemisphere, the model well captures the ozone enhancements over the continental regions of Eurasia and North America. In spring time for the Southern Hemisphere (SON), outflow of high ozone in the mid-latitudes from biomass burning in South America and Africa is also well reproduced by the model. On the other hand, the model appears to underestimate ozone abundances in the northern high latitudes, including the Arctic for spring and summer. We found that this underestimation of tropospheric ozone partly compensates for the general overestimation of the column ozone amount in the northern high latitudes as described above. These features of our model simulation suggest that further improvement and validation of chemical processes are still required for the modeling framework of MIROC-ESM-CHEM.

\subsection{Land surface and terrestrial ecosystems}

The leaf area index (LAI) fraction predicted by MIROCESM-CHEM in each grid is shown in Fig. 19a. The color indicates fractional coverage of LAI from three ecosystem components, trees, natural grass, and agricultural, and these components may coexist in the same grid cell. The first component, "trees", is the fraction of LAI comprising all woody PFTs in primary and secondary vegetation. The second, "natural grass", which is the LAI fraction of grasslands without anthropogenic land use. The third component is "agricultural", which is the LAI fraction consisting of crops and pasture. Except for the case when total LAI is zero, the sum total of these three fractions is 1 . Therefore, this map indicates the relative abundance of the above three ecosystems as a result of competition among PFTs and of historical human influence on vegetation through the land use change. Natural grasslands reproduced by the model seem to exist only in the north circumpolar region and other limited regions. This could be explained by two reasons: first, MIROC-ESMCHEM failed to capture dry and non-tree area, and represents these areas as the ecosystem with the coexistence of grass and trees. Second, in the model forcing for land use change, most grassland expanding in dry and temperate region is categorized into pasture because they include the area grazed by 
(a) LW Net

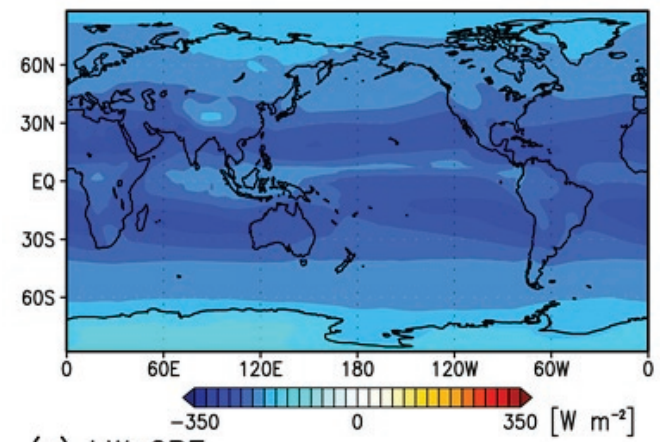

(c) LW CRF

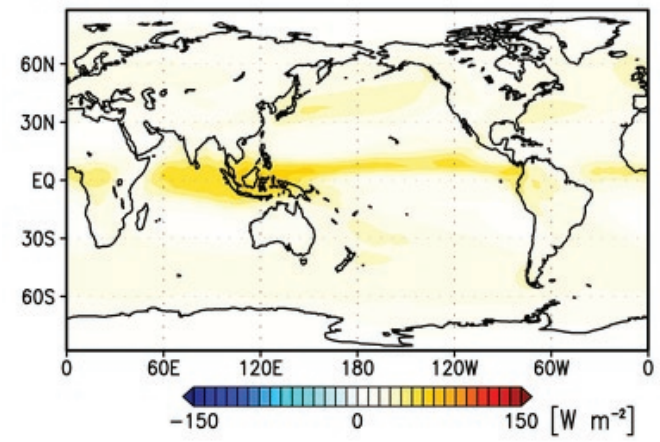

(b) LW Net, Bias

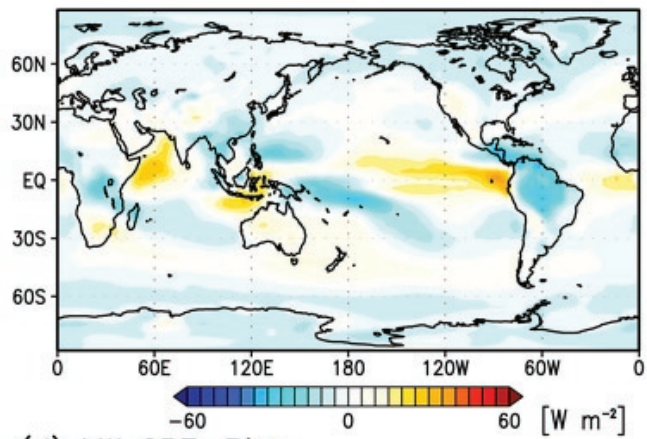

(d) LW CRF, Bias

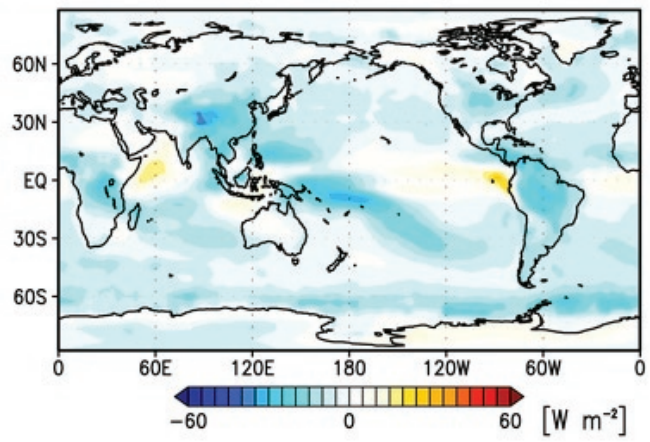

Fig. 9. Annual mean net downward (a, b) longwave (LW) radiation at the top of the atmosphere (TOA), and (c, d) SW cloud radiative forcing (CRF) at the TOA. Results of the model simulation are shown in (a, c), and the model bias against ERBE observations (Barkstrom et al., 1989) is shown in (b, d) (see text).

nomadic livestock as well as the pasture that is enclosed.

Total vegetation biomass consisting of leaf, stem, and root was $353 \mathrm{PgC}$ for the 2000-2005 average, which is at the lower end of previous reports: $560 \mathrm{Pg} \mathrm{C}$ in Ajtay et al. (1979), $359 \mathrm{Pg} \mathrm{C}$ in Dixon et al. (1994), and 466-654 Pg C in Prentice et al. (2001). This is because artificial disturbances to vegetation carbon through land use change, forest cutting, gradual forest recovery from abandoned agricultural area, annual harvesting of crops, continuous livestock grazing in pasture and its recovery, are incorporated in the present model, while previous models deal with the potential vegetation only in the absence of artificial disturbance (Friedlingstein et al., 2006; Sitch et al., 2008) or only consider the natural vegetation and croplands (Kato et al., 2009; Matthews et al., 2005; Meissner et al., 2003). As a result, the predicted value of vegetation carbon tends to be lower than that of previous applications of terrestrial ecosystem models. Recent aggregated results of forest statics considering human impacts revealed that the forest carbon stock is less than $300 \mathrm{Pg} \mathrm{C}$ (Kindermann et al., 2008), which is even lower than the $338 \mathrm{Pg} \mathrm{C}$ estimated from our model.

The distribution pattern of forest biomass based on observations and reproduced by MIROC-ESM-CHEM are shown in (Fig. 19b and c). Forest carbon in the tropical regions such as South America and Africa carbon was generally underpredicted, while the South and Southeast Asia were overestimated. The extent of forests and moderate accumulations of carbon in temperate and boreal regions were well reproduced. Regions with low forest biomass are located in deserts, semi-arid regions, and agricultural areas of Europe, Asia, and North America. Although the model can correctly predict the location of deserts in the Northern Hemisphere, it failed to capture the semi-arid or desert areas in Australia and steppe and savanna in southern Africa. This failure is due to the high sensitivity of plants to soil moisture in the terrestrial ecosystem model and a positive precipitation bias in these areas.

The total simulated soil organic carbon including litter was $2511 \mathrm{Pg} \mathrm{C}$, which is slightly higher than the estimates of soil inventories to a few meters depth (2376-2456 Pg C in Batjes, 1996, $2344 \mathrm{Pg} \mathrm{C}$ in Jobbagy and Jackson, 2000). After linearly scaling to $1 \mathrm{~m}$ depth (in our model, the soil grid system for soil decomposition assumes $1.5 \mathrm{~m}$ depth), the amount of soil organic carbon was $1717 \mathrm{Pg} \mathrm{C}$, which is within the range of $1395-2070 \mathrm{Pg} \mathrm{C}$ previously reported as the carbon stored in the 0-100 cm depth (Ajtay et al., 1979; Batjes, 1996; Post et al., 1982; Prentice et al., 2001; IGBP-DIS, 2000). However, there is still large uncertainty for the estimates of the total soil organic carbon as there are not enough samples for the soil organic carbon especially in deeper layer (Tarnocai et al., 
(a) Atmospheric Temperature [K]

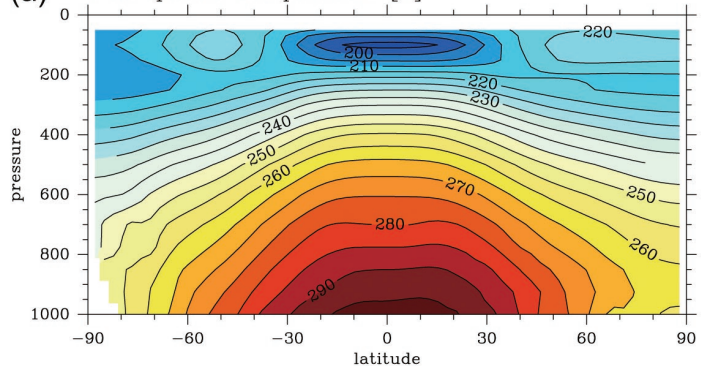

(c) Specific humidity $\left[\mathrm{x} 10^{-3} \mathrm{~kg} / \mathrm{kg}\right]$

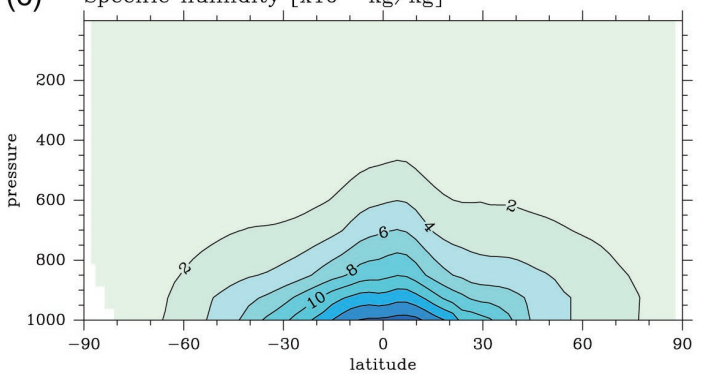

(e) Relative humidity [\%]

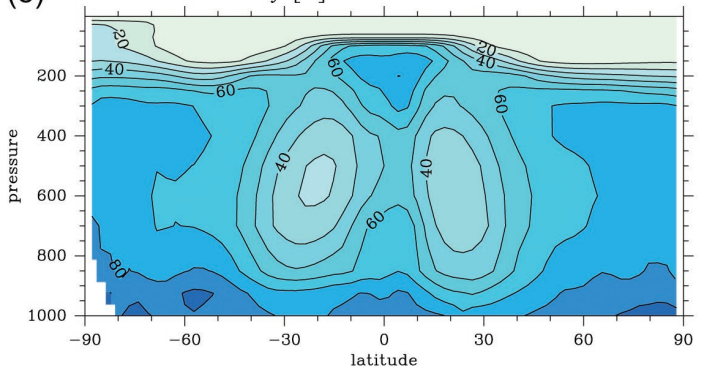

(b) Temperature Bias [K]

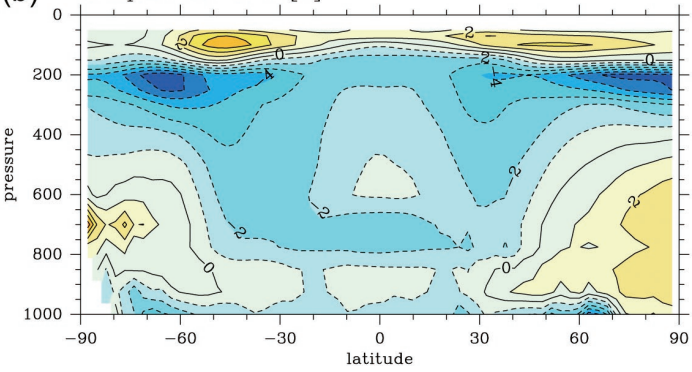

(d) Specific humidity Bias $\left[\times 10^{-3} \mathrm{~kg} / \mathrm{kg}\right]$

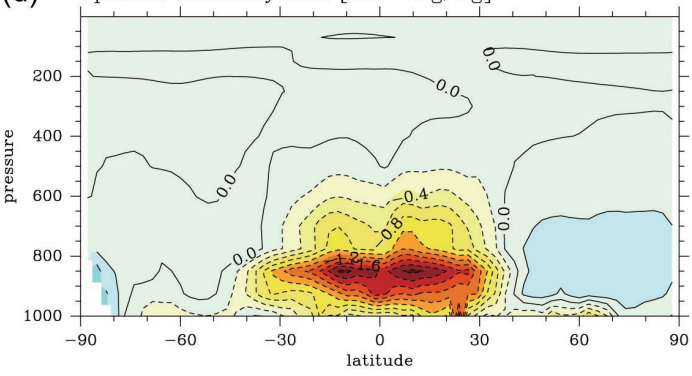

(f) Relative humidity Bias [\%]

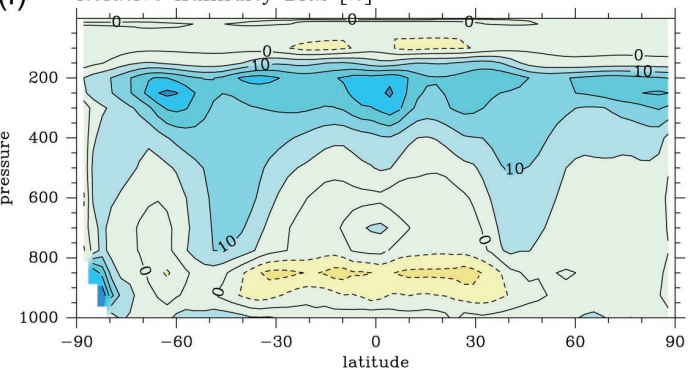

Fig. 10. Zonal mean of annual averaged model climatology (1980-1999) for (a) atmospheric temperature, (c) specific humidity, and (e) relative humidity. Differences between the model climatology and ERA-40 data are displayed in (b), (d), and (f), respectively.

2009) and the amounts of soil organic carbon estimated by the model is strongly affected by it's settings (e.g. the number of soil pool, turnover rate in decomposition, and effects from soil water and temperature). In addition, as the mechanisms for the high accumulation of soil carbon like frozen carbon or peat in the north circumpolar regions are not well known, global terrestrial ecosystem models represent these processes implicitly with the lack of precise mechanism of the interaction between physical environment and soil carbon dynamics.

The model was able to capture the global trend of large accumulations of soil organic carbon in boreal and tundra regions in Eurasia and North America, and small accumulations in tropical and extra-tropical regions (Fig. 19e). Compared with the observation (IGBP-DIS, 2000; Fig. 19d), the model overestimated the soil carbon in mountainous or plateau areas such as the Rocky Mountain, Tibetan plateau, and a chain of mountains in east Siberia, likely due to the overestimation of vegetation biomass. The reason for these overestimate in vegetation carbon is that the growth conditions for vegetation in complicated terrain with high altitude cannot be correctly represented in coarse grid systems.

Compared with the satellite-based observations (Zhao et al., 2005), the spatial distribution and its magnitude of GPP (Gross Primary Production) was well reproduced by our model (Fig. 19f and g). The global GPP of terrestrial ecosystems averaged over $2000-2005$ was $134 \mathrm{Pg} \mathrm{C} \mathrm{yr}^{-1}$, which is comparable with other model estimates and present day observations (127.9 $\mathrm{Pg} \mathrm{Cyr}^{-1}$ in Ito, 2005; $137 \mathrm{Pg} \mathrm{C} \mathrm{yr}^{-1}$ in Krinner et al., 2005; $184-187 \mathrm{Pg} \mathrm{Cyr}^{-1}$ in Meissner et al., 2003; $109.29 \mathrm{PgC} \mathrm{yr}^{-1}$ in Zhao et al., 2005; 119.6 $\mathrm{PgC} \mathrm{yr}^{-1}$ in Sarmiento and Gruber, 2002). The global total of NPP (Net Primary Production) averaged over 20002005 was $64.3 \mathrm{PgC} \mathrm{yr}^{-1}$, which also falls within the ranges of several model estimates (44.4-66.3 $\mathrm{Pg} \mathrm{C} \mathrm{yr}^{-1}$ under 19311960 climate conditions: Cramer et al., 1999) and compare reasonably with other estimates $\left(59.9 \mathrm{Pg} \mathrm{C} \mathrm{yr}^{-1}\right.$ in $\mathrm{Aj}$ tay et al., 1979; 59.6 $\mathrm{Pg} \mathrm{Cyr}^{-1}$ in Sarmiento and Gruber, 2002; 56.0 $\mathrm{Pg} \mathrm{C} \mathrm{yr}^{-1}$ in Zhao et al., 2005). Global emissions without autotrophic respiration (i.e. the sum of heterotrophic 

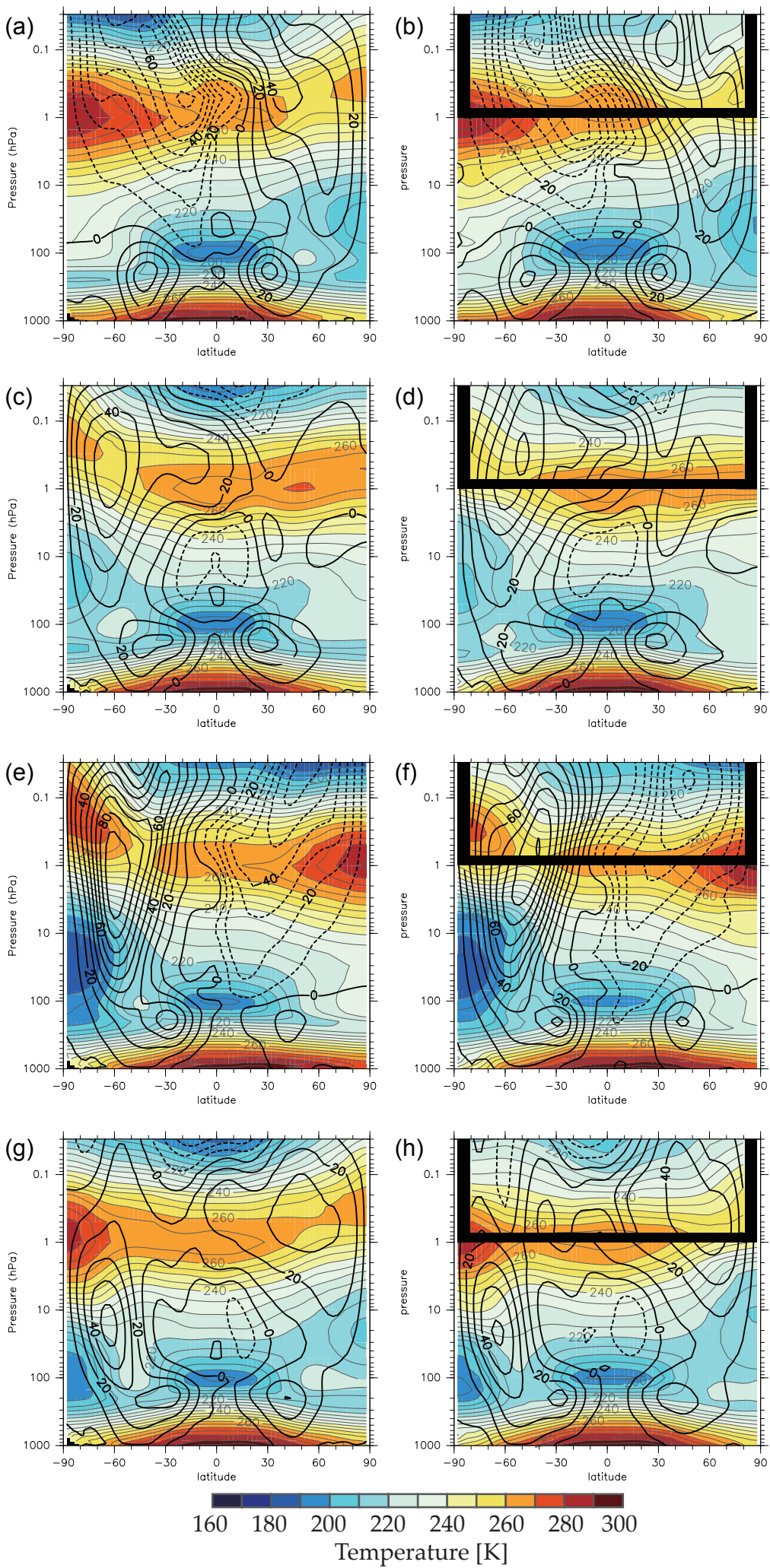

Fig. 11. Zonal-mean zonal winds and temperatures in (a, b) January, (c, d) April, (e, f) July, and (g, h) October. Left column shows model climatology (1980-1999), and the right column shows observed climatology: ERA-40 (1980-1999) below the 1 hPa level and CIRA86 (1975-1978) above. 

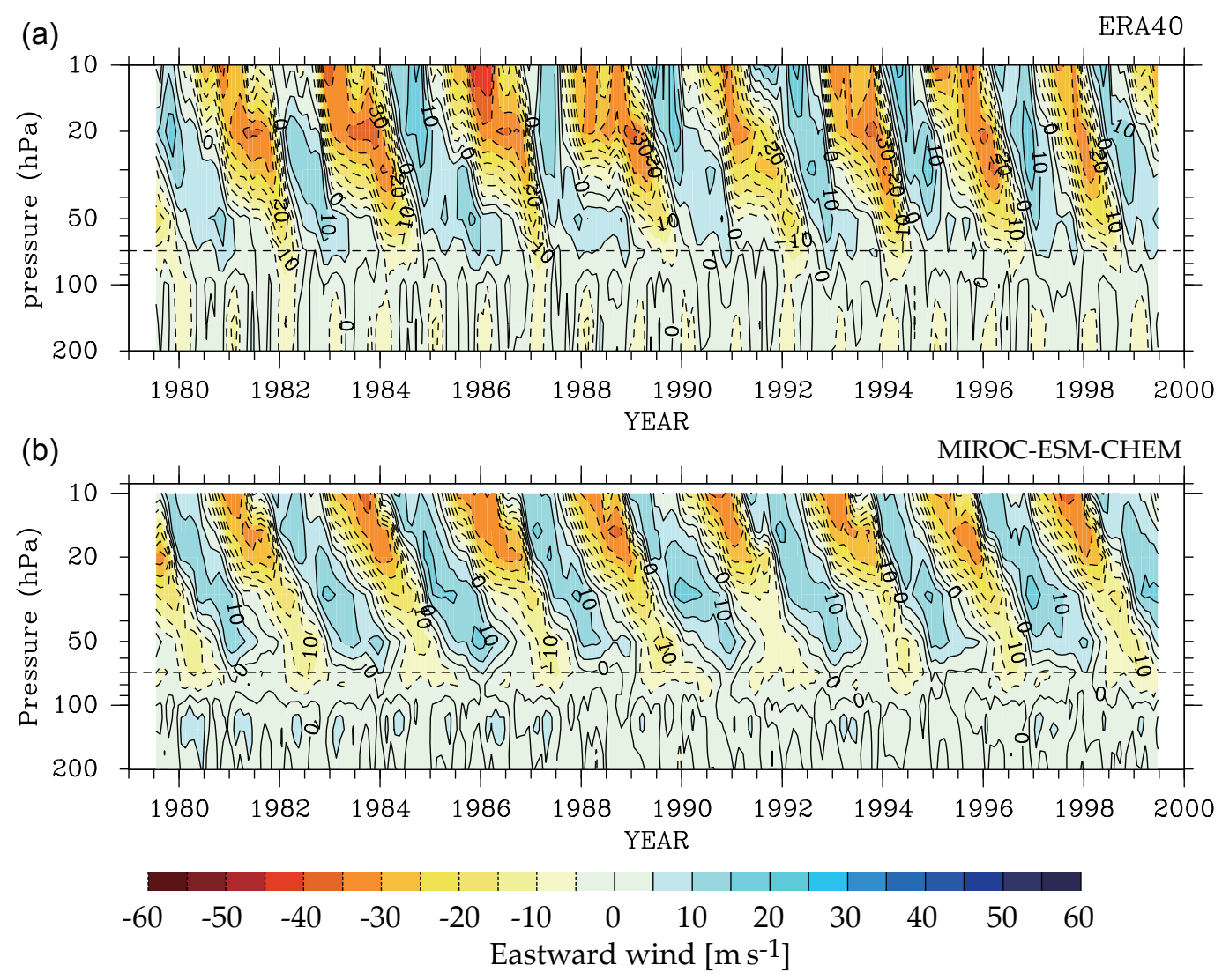

Fig. 12. Zonal-mean zonal winds over the equator for (a) ERA-40 and (b) the model result.

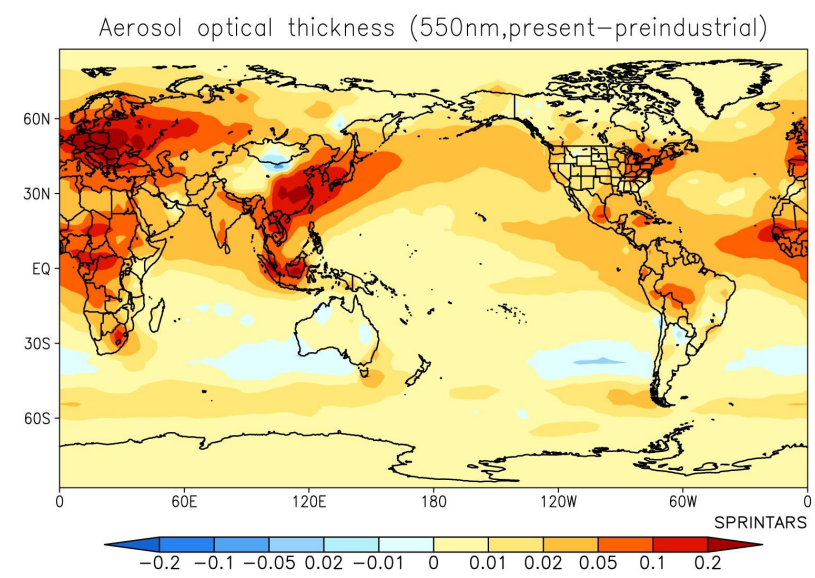

Fig. 13. Anomaly of the aerosol optical thickness averaged for the period 1991-2000 relative to the period 1851-1860.

respiration and gross land use emissions) was $62.8 \mathrm{Pg} \mathrm{C} \mathrm{yr}^{-1}$. The resultant net carbon fluxes from the atmosphere to land (net biome production) in the 1990s and 2000-2005 were 1.34 and $1.50 \mathrm{PgC} \mathrm{yr}^{-1}$, respectively, which are within the range reported by Denman et al. (2007).

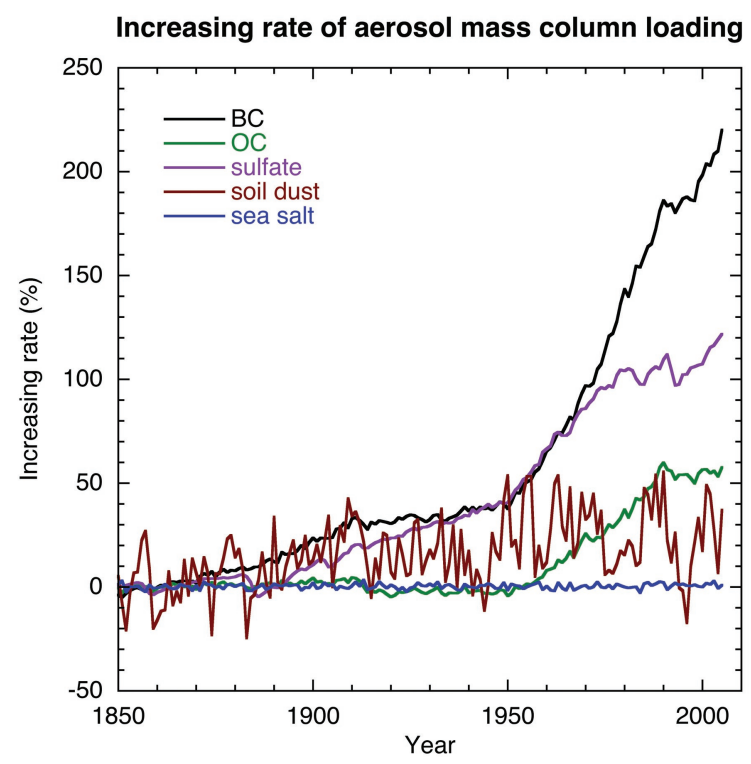

Fig. 14. Time evolution of global annual mean increasing rate of mass column loading for each aerosol component relative to the mean of the period $1851-1860$. 


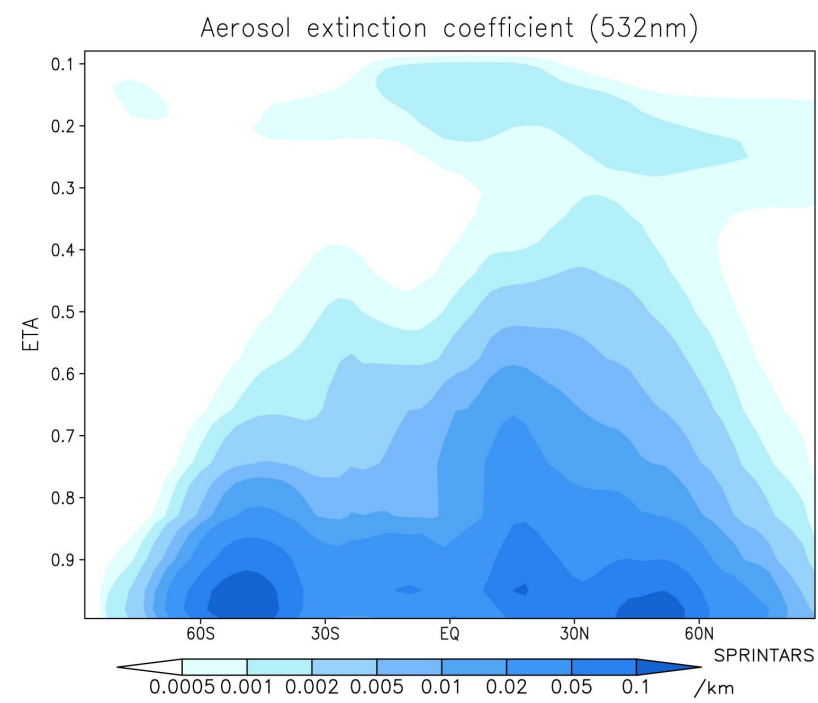

Fig. 15. Anomaly of the zonal-mean aerosol extinction coefficient averaged for the period 1991-2000 relative to the period 18511860.

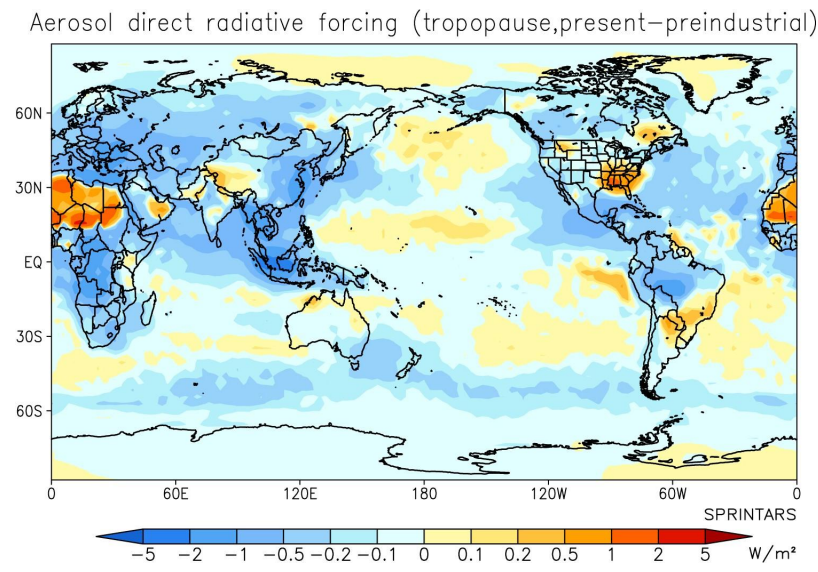

Fig. 16. Annual mean radiative forcing of the aerosol direct effect under all-sky conditions in the year 2000 relative to 1850 .

In MIROC-ESM-CHEM, the distribution and communities of vegetation, biomass, and the leaf amount are dynamically determined by SEIB-DGVM. It is therefore important to reproduce the relation between climate and terrestrial ecosystems properly in evaluating the climate sensitivity including those feedback processes. Suzuki et al. (2006) examined the relation between climate zones and vegetation distribution using the global observation datasets. The climatological condition for vegetation growth was evaluated by the warmth index (WAI) and the wetness index (WEI), and they were compared with the normalized difference vegetation index (NDVI), which represents the greenness of land ecosystems. Figure 20a is a scatter plot of the WEI and the WAI with the color tones according to the NDVI, after Fig. 2

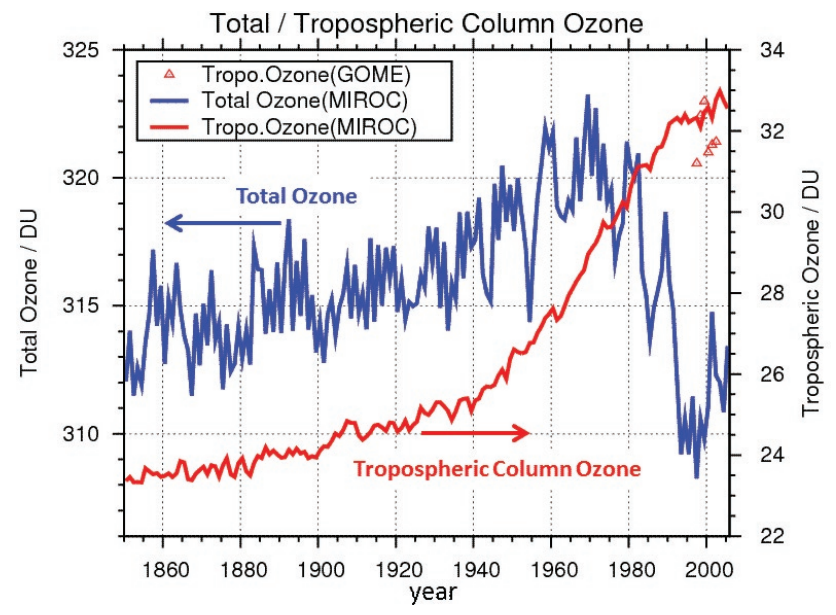

Fig. 17. Time series of global mean total and tropospheric ozone column abundance in Dobson Units simulated by the MIROCESM-CHEM (blue and red lines, respectively). Triangles represent tropospheric column ozone derived from satellite measurements (GOME) for around 2000.

of Suzuki et al. (2006). The NDVI was large where both WEI and WAI were high, while the NDVI was small where either the WEI or the WAI were low.

Figure 20b shows a scatter plot of WEI and WAI with color tones according to the LAI calculated by MIROCESM-CHEM. The colors for the logarithmic LAI are adapted to follow the colors for the NDVI in Fig. 20a, since the increasing rate of NDVI is generally lower for larger LAI. (Myneni et al., 2002). The general shape of the scatter plot for WEI and WAI is similar to that in Fig. 20a. MIROC-ESMCHEM also reproduces the features of large LAI in regions where WEI and WAI are high, and small LAI where WEI or WAI is low. However, points with a small WAI and a large WEI were fewer than observation. That is probably due to the overestimation of surface air temperature in the warm season over the continents in MIROC-ESM-CHEM.

\subsection{Ocean and marine ecosystems}

The ocean circulation model is three dimensional and driven by the surface wind stress and tracer stratification. The properties of sea water may vary by vertical and horizontal mixing of different water masses, but the tracer distribution over a large scale is difficult to change in the model after the spinup. In order to investigate the properties of sea water and their formation, the tracer vertical distributions are analyzed.

Figure 21 displays the Atlantic meridional sector of sea temperature, salinity, and nutrients. The Atlantic surface water has the warmest and saltiest water and is also poorest in nutrients compared to deeper layers. With the subtropical gyres in both hemispheres divided by the equatorial upwelling, the meridional vertical section of these tracers 


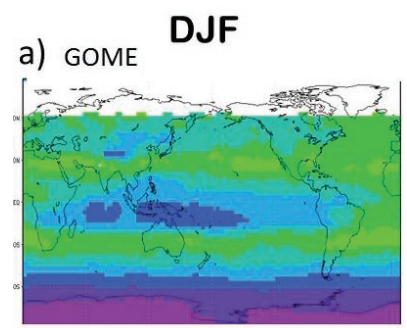

MAM

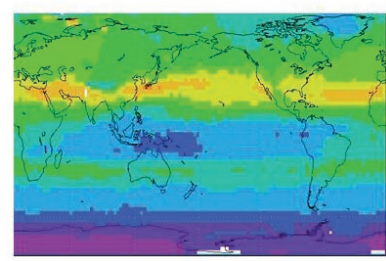

b) MIROC-ESM-CHEM

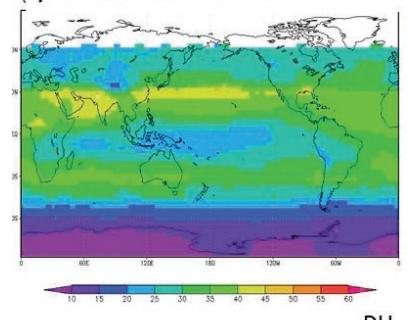

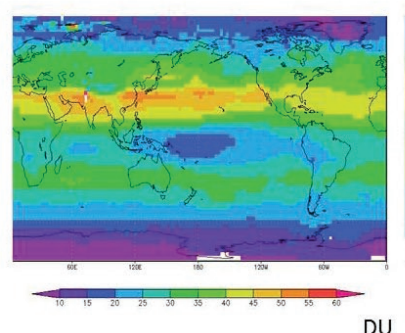

JJA
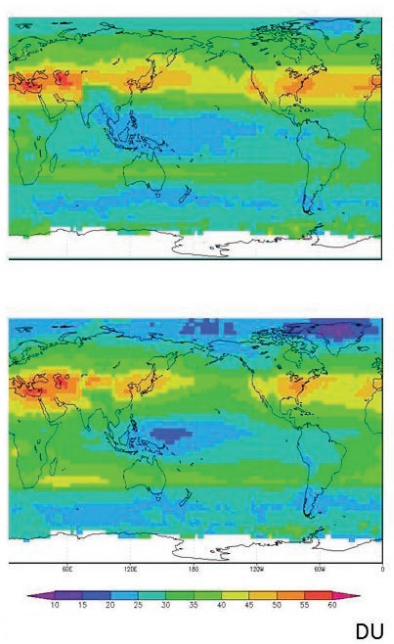

SON
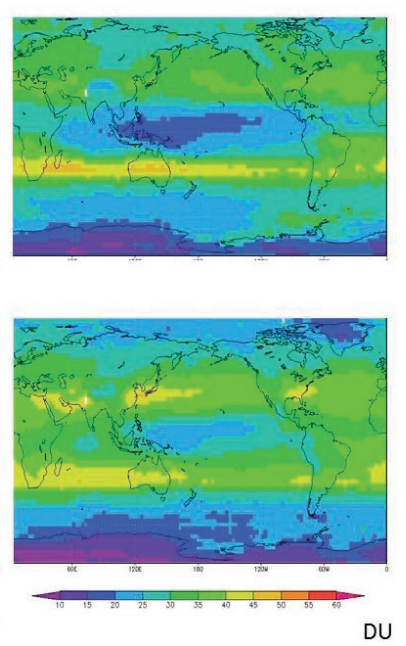

Fig. 18. Tropospheric column ozone distributions (a) observed by GOME for 2000 and (b) calculated by the model for distinct seasons. The modeled ozone is shown as an average of simulations for 2000-2003 (using the averaging kernel for GOME 2000).

describes a W-shape for a few hundred meters depth from the surface.

The next layer of subsurface water is called Antarctic Intermediate Water (AAIW), which slides down from the surface in the Southern Ocean to $1 \mathrm{~km}$ depth in the tropics. The AAIW is relatively fresh (low salinity), rich in nutrients, and the lowest in temperature at around 100-200 m depth.

Below the AAIW, at a depth of 1000-4000 m, the North Atlantic Deep Water (NADW) fills most of the Atlantic basin with more saline and low nutrient water which originates from the high northern latitudes, but reaches as far south as $40^{\circ} \mathrm{S}$ and beyond.

At the bottom of the Atlantic Ocean, the Antarctic Bottom Water (AABW) consists of the coldest and nutrient rich but less saline water.

Compared to the observations (Conkright et al., 2002), the AAIW and AABW are reasonably well simulated by the model, while the NADW looks to be weakly formed, probably due to stable stratification near the surface. The Atlantic meridional overturning cell is also somewhat weakly resolved, as the maximum stream function across $30^{\circ} \mathrm{N}$ is around $15 \pm 1 \mathrm{~Sv}$, but is still in a valid range.

Phytoplankton are the microscopic organisms responsible for ocean primary production, and play an important role in controlling the ocean-atmosphere $\mathrm{CO}_{2}$ flux, and hence the global carbon cycle. In order to validate the biogeochemistry-capable general circulation model, the spatio-temporal variability of phytoplankton is analyzed.

Figure 22 illustrates the seasonal variation of sea surface chlorophyll in the central Pacific, around the international dateline. Both the satellite observation and model simulation show the sinusoidal curves of meridional migration with time because the solar insolation is a factor for the chlorophyll growth. Another chlorophyll growth factor is the nutrient supply. The phytoplankton spring bloom initiates around March (October) in the North (South) subpolar Pacific, as solar insolation and the nutrient supply increases and the vertical mixing activates. The North (South) Pacific spring bloom is underestimated (overestimated) in the simulation mainly due to the underestimated (overestimated) nutrient distributions beneath.

Other biases are visible at the equator and around $15^{\circ} \mathrm{N}$. These biases are caused by unrealistic strong trade winds in the central to western Pacific which often appear in atmosphere-ocean coupled general circulation models. The anomalous strong easterly winds further enhance the equatorial upwelling and the development of a cold tongue in the boreal summer, and also enhance upwelling where the easterly wind velocity is at a maximum, by enhancing the northward (southward) transport to the north (south).

In summary, some biases are found in the ocean circulation model simulation results but these arise from errors in inputs from other components of the model, and all are reasonable. The seasonality in ocean processes is fairly well simulated.

\section{Concluding remarks}

In this study, the MIROC-ESM has been fully described and results for the CMIP5 historical simulation have been evaluated from several perspectives: atmosphere, ocean, sea-ice, land-surface, ocean and terrestrial biogeochemistry, and atmospheric chemistry and aerosols. The atmospheric chemistry coupled version of MIROC-ESM (MIROC-ESMCHEM) reasonably reproduces the transient variations in global mean SAT throughout $1850-2005$, as well as the 

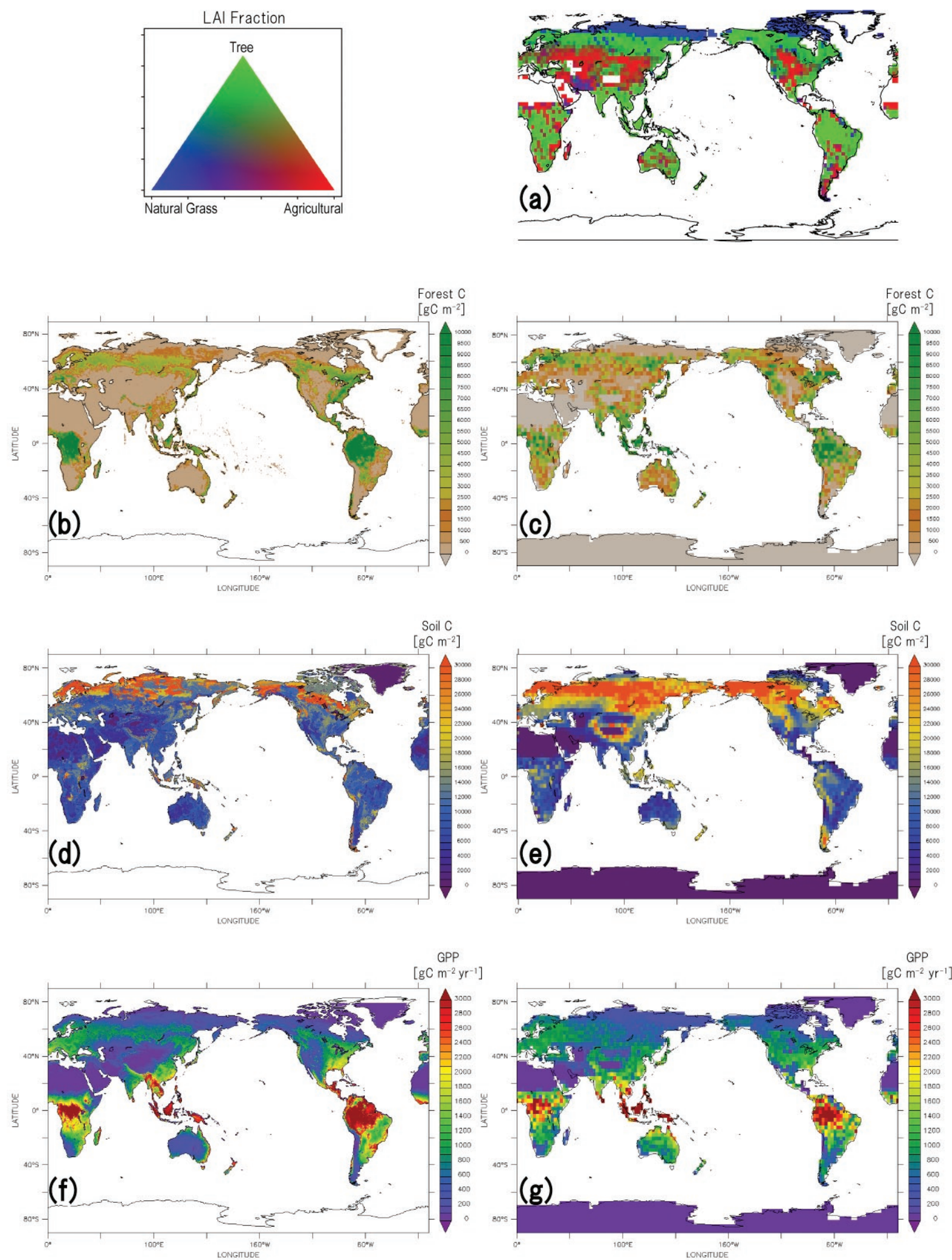

Fig. 19. (a) LAI fraction predicted by the model. (b) Forest carbon from Kindermann et al. (2008). (c) Model-predicted forest carbon. (d) Soil carbon to $1 \mathrm{~m}$ depth from IGBP-DIS (2000). (e) Model-predicted soil carbon linearly scaled to $1 \mathrm{~m}$ depth. (f) Gross primary production from Zhao et al. (2005). (g) Model predicted gross primary production. All model outputs are the results averaged over 2000-2005. 

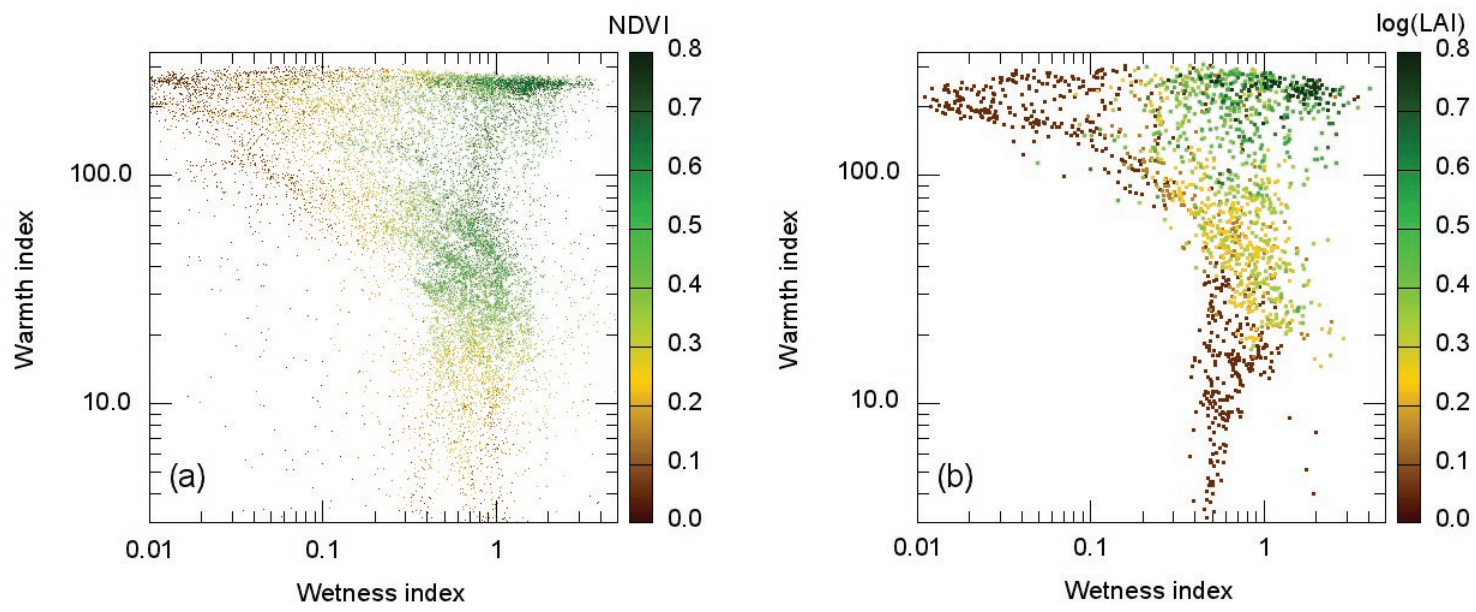

Fig. 20. (a) Observation-based relation of WEI (wetness index), WAI (warmth index), and NDVI (normalized differential vegetation index) over the global continents at 1 degree resolution. The NDVI value is shown by color at the intersection of WEI and WAI. (b) As in (a), but for the model result. The colors are for the logarithmic LAI, and at the model resolution (T42).
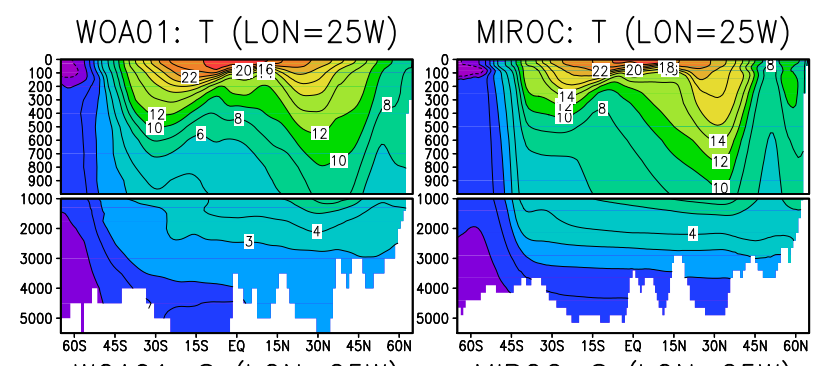

WOA01: $S(L O N=25 W)$

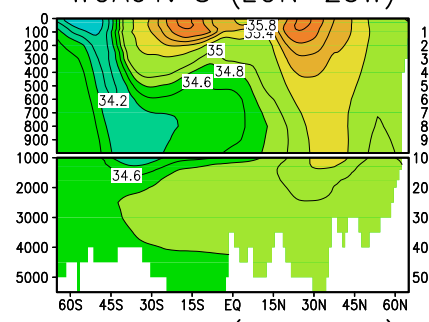

WOA01: $N(L O N=25 W)$
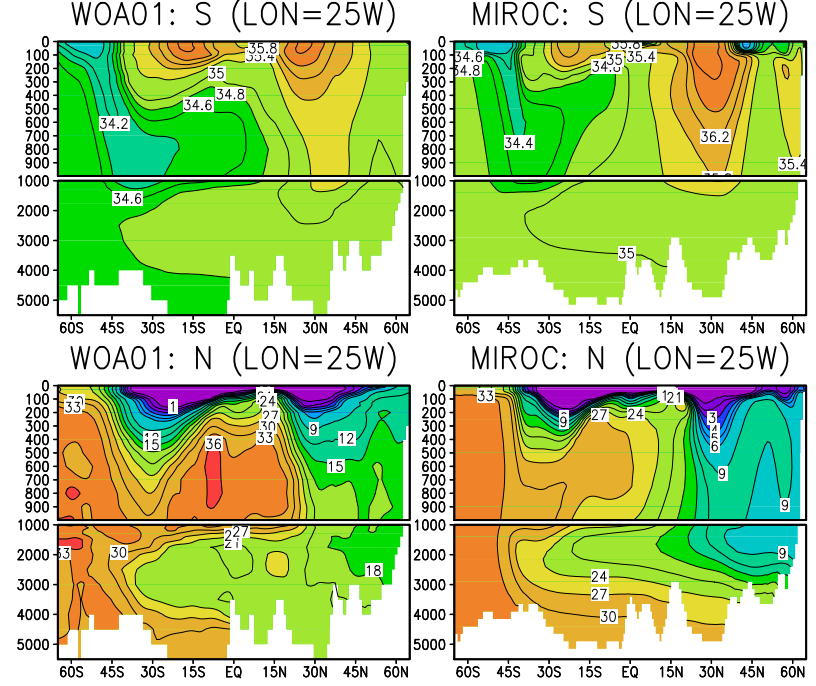

Fig. 21. Annual mean climatology of the Atlantic latitude-depth sector at $25^{\circ} \mathrm{W}$ : sea water potential temperature $(T, \operatorname{degC})$, salinity $(S, \mathrm{PSU})$, and nutrients $\left(N, \mathrm{mmol} \mathrm{N} \mathrm{m}^{-3}\right)$, for the observations (WOA01) (left column) and simulation (MIROC-ESM-CHEM) (right column).

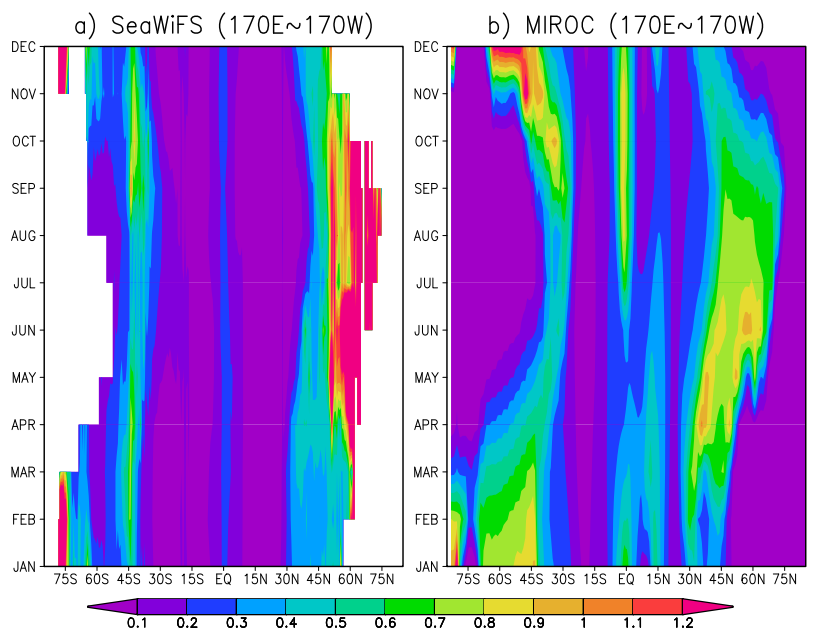

Fig. 22. Time-latitude Hovmoeller diagram of the sea surface chlorophyll density $\left(\mathrm{mg} \mathrm{Chl} \mathrm{m}^{-3}\right)$ around the international dateline (zonally averaged for $170^{\circ} \mathrm{E}-170^{\circ} \mathrm{W}$ ) for (a) satellite observation (SeaWiFS) and (b) the simulation (MIROC-ESM-CHEM). Note that the satellite observation is missing data in the polar night or under sea-ice because the SeaWiFS measures the chlorophyll remotely by the ocean surface color.

geographical distribution of SAT trends. The climatological distribution of SAT generally agrees with observations, but shows a systematic warm bias in the northern mid- and high latitudes and over Antarctica and a cold bias over the tropics. These temperature biases are likely associated with over-/under-estimations of low-level clouds, as seen in the TOA OSR biases. The model has the systematic dry bias in the tropical lower troposphere, which could cause the underestimation of low-level clouds. The simulated present-day 
climatology of the zonal-mean zonal winds and temperatures in the stratosphere and mesosphere generally agree with the observations, and the model self-consistently generates the equatorial QBO in the lower stratosphere. The aerosol module simulates the historical evolution of aerosols in terms of changes in the optical thickness, column mass loading, extinction coefficient, and direct effect, based on the RCP historical emissions. The simulated present-day tropospheric column ozone distribution shows reasonable agreement with satellite observations, although several systematic errors are pointed out. The terrestrial carbon cycle component simulates realistic geographical distributions of LAI, GPP, vegetation biomass, and soil organic carbon. The ocean GCM and marine biogeochemistry component generally simulates the observed latitude-depth distributions of potential temperatures, salinity, and nutrients in the Atlantic sector, as well as seasonal variations in chlorophyll over the Pacific sector.

Overall, MIROC-ESM-CHEM generally shows good performance in the reproduction of the earth system in the historical period. The model has also been used for several mandatory simulations of CMIP5, while the atmospheric chemistry uncoupled version (MIROC-ESM) has been used to conduct a wider variety of simulations. Although the general results of MIROC-ESM and MIROC-ESM-CHEM agree with each other in terms of historical evolution of SAT, aerosols, sea-ice, land surface, and the terrestrial and marine biogeochemistry, there are several fundamental differences between the two versions. For instance, ozone concentration is predicted in MIROC-ESM-CHEM, while prescribed in MIROC-ESM. The prescribed ozone includes effects of historical evolution of tropospheric ozone precursors and halogen species destroying the stratospheric ozone, but effects of the solar cycle and QBO on the ozone concentration are neglected in the current setup (Kawase et al., 2011). In this context, MIROC-ESM-CHEM seems to have a higher potential to realistically reproduce climate variability in the stratosphere. Further evaluations of the simulated climate fields are required for both versions, along with the simulated biogeochemistry parameters.

Several papers on the analyses of our CMIP5 simulations have already been published in peer-reviewed journals. For example, Watanabe et al. (2011) and Watanabe and Yokohata (2011) demonstrate the projected future evolution of the surface ultraviolet radiation and attribute its potential changes to future changes in column ozone, aerosols, clouds, and surface albedo. Watanabe and Kawatani (2011) focus on the future evolution of the equatorial QBO associated with climate change.

Acknowledgements. The authors would like to thank two referees for their constructive comments on the original manuscript. They also thank Team-MIROC for their support and encouragement throughout the project. Discussions with Hideharu Akiyoshi were helpful to improve the atmospheric chemistry component. We thank Rikie Suzuki for providing the global datasets of observation-based climatology and vegetation indices. This study was supported by the Innovative Program of Climate Change Projection for the 21st century, MEXT, Japan. The numerical simulations in this study were performed using the Earth Simulator, and figures were drawn using GTOOL and the GFD-DENNOU Library. This study is supported in part by the Funding Program for Next Generation World-Leading Researchers by the Cabinet Office, Government of Japan (GR079).

Edited by: O. Boucher

\section{References}

Adler, R. F., Huffman, G. J., Chang, A., Ferraro, R., Xie, P., Janowiak, J., Rudolf, B., Schneider, U., Curtis, S., Bolvin, D., Gruber, A., Susskind, J., and Arkin, P.: The Version 2 Global Precipitation Climatology Project (GPCP) Monthly Precipitation Analysis (1979-Present), J. Hydrometeor., 4, 1147-1167, 2003.

Ajtay, G. L., Kenter, P., and Duvigneaud, P.: Terrestrial primary production and phytomass, in: The Global Carbon Cycle, edited by: Bolin, B., Degens, E. T., Kempe, S., and Ketner, P., New York, USA, John Wiley \& Sons, 129-181, 1979.

Akiyoshi, H., Sugita, T., Kanzawa, H., and Kawamoto, N.: Ozone perturbations in the Arctic summer lower stratosphere as a reflectio in of NOx chemistry and wave activity, J. Geopys. Res., 109(D03), D03304, doi:10.1029/2003JD003632, 2004.

Aoki, T., Motoyoshi, H., Kodama, Y., Yasunari, T. J., Sugiura, K., and Kobayashi, H.: Atmospheric Aerosol Deposition on Snow Surfaces and Its Effect on Albedo, Sci. Online Lett. Atmos., 2, 13-16. doi:10.2151/sola.2006-004, 2006.

Arakawa, A. and Schubert, W. H.: Interactions of cumulus cloud ensemble with the large-scale environment, Part I, J. Atmos. Sci., 31, 674-701, doi:10.1175/15200469(1974)031<0674:IOACCE > 2.0.CO;2, 1974.

Barkstrom, B. R., Harrison, E. F., Smith, G., Green, R., Kibler, J., Cess, R., and ERBE Science Team: Earth Radiation Budget Experiment (ERBE) archival and results, B. Am. Meteorol. Soc., 70, 1254-1262, April 1985, 1989.

Batjes, N. H.: Total carbon and nitrogen in the soils of the world, Euro. J. Soil Sci., 47, 151-163, 1996.

Bonan, G. B.: Forests and climate change: Forcings, feedbacks, and the climate benefits of forests, Science, 320, 1444-1449, doi:10.1126/science.1155121, 2008.

Bougamont, M., Bamber, J. L., and Greuell, W.: A surface mass balance model for the Greenland Ice Sheet, J. Geophys. Res. 110, F04018, doi:10.1029/2005JF000348, 2005.

Brasseur, G. P., Hauglustaine, D. A., Walters, S., and Rasch, P. J.: MOZART, a global chemical transport model for ozone and related chemical tracers, 1. Model description, J. Geophys. Res., 103, 28265-28289, 1998.

Brohan, P., Kennedy, J. J., Harris, I., Tett, S. F. B., and Jones, P. D.: Uncertainty estimates in regional and global observed temperature changes: A new data set from 1850, J. Geophys. Res., 111, D12106, doi:10.1029/2005JD006548, 2006.

Coleman, K. and Jenkinson, D. S.: ROTHC-26.3, A model for the turnover of carbon in soils, available at: http://www. rothamsted.bbsrc.ac.uk/Research/Centres/home.php, last access: 2010, 1999.

Conkright, M. E., Locarnini, R. A., Garcia, H. E., B’Brien, T. D., Boyer, T. P., Stephens, C., and Antnov, J. I.: World Ocean At- 
las 2001: Objective Analyses, Data Statistics, and Figures, CDROM Documentation, National Oceanographic Data Center, Silver Spring, MD, 17 pp., 2002.

Cox, P., Betts, R., Jones, C., Spall, S., and Totterdell, I.: Acceleration of global warming due to carbon-cycle feed-backs in a coupled climate model, Nature, 408, 184-187, 2000.

Cramer, W., Kicklighter, D. W., Bondeau, A., Moore III, B., Churkina, G., Nemry B., Ruimy, A., Schloss, A. L., and the participants of the Potsdam NPP model intercomparison: Comparing global models of terrestrial net primary productivity (NPP): overview and key results, Glob. Change Biol., 5, 1-15, 1999.

Denman, K. L., Brasseur, G., Chidthaisong, A., Ciais, P., Cox, P. M., Dickinson, R. E., Hauglustaine, D., Heinze, C., Holland, E., Jacob, D., Lohmann, U., Ramachandran, S., da Silva Dias, P. L., Wofsy, S. C., and Zhang, X.: Couplings Between Changes in the Climate System and Biogeochemistry, in: Climate Change 2007: The Physical Science Basis. Contribution of Working Group I to the Fourth Assessment Report of the Intergovernmental Panel on Climate Chnage, edited by: Solomon, S., Qin, D., Manning, M., Chen, Z., Marquis, M., Averyt, K. B., Tignor, M., and Miller, H. L., Cambridge University Press, Cambridge, United Kingdom and New York, NY, USA, 499-588, 2007.

Dixon, R. K., Brown, S., Houghton, R. A., Solomon, A. M., Trexler, M. C., and Wisniewski, J.: Carbon Pools and Flux of Global Forest Ecosystems, Science, 263, 185-190, 1994.

Emori, S., Nozawa, T., Numaguchi, A., and Uno I., Importance of cumulus parameterization for precipitation simulation over east Asia in June, J. Meteorol. Soc. Jpn., 79, 939-947, doi:10.2151/jmsj.79.939, 2001.

Fleming, E. L., Chandra, S., Barnett, J. J., and Corney, M.: Zonal mean temperature, pressure, zonal wind, and geopotential height as functions of latitude, COSPAR International Reference Atmosphere: 1986, part II: Middle atmosphere Models, Adv. Space Res., 10, 11-59, doi:10.1016/0273-1177(90)90386-E, 1990.

Fountoukis, C. and Nenes, A.: ISORROPIA II: a computationally efficient thermodynamic equilibrium model for $\mathrm{K}^{+} \mathrm{Ca}_{2}^{+} \mathrm{Mg}_{2}^{+} \mathrm{NH}_{4}^{+} \mathrm{Na}^{+} \mathrm{SO}_{4}^{2-} \mathrm{NO}_{3}^{-} \mathrm{Cl}^{-} \mathrm{H}_{2} \mathrm{O}$ aerosols, Atmos. Chem. Phys., 7, 4639-4659, doi:10.5194/acp-7-4639-2007, 2007.

Friedlingstein, P., Cox, P., Betts, R., Bopp, L., von Bloh, W., Brovkin, V., Cadule, P., Doney, S., Eby, M., Fung, I., Bala, G., John, J., Jones, C., Joos, F., Kato, T., Kawamiya, M., Knorr, W., Lindsay, K., Matthews, H. D., Raddatz, T., Rayner, P., Reick, C., Roeckner, E., Schnitzler, K.-G., Schnur, R., Strassmann, K., Weaver, A. J., Yoshikawa, C., and Zeng, N.: Climate-carbon cycle feedback analysis: Results from the C4MIP model intercomparison, J. Clim., 19(14), 3337-3353, doi:10.1175/JCLI3800.1, 2006.

Gauss, M., Myhre, G., Isaksen, I. S. A., Grewe, V., Pitari, G., Wild, O., Collins, W. J., Dentener, F. J., Ellingsen, K., Gohar, L. K., Hauglustaine, D. A., Iachetti, D., Lamarque, F., Mancini, E., Mickley, L. J., Prather, M. J., Pyle, J. A., Sanderson, M. G., Shine, K. P., Stevenson, D. S., Sudo, K., Szopa, S., and Zeng, G.: Radiative forcing since preindustrial times due to ozone change in the troposphere and the lower stratosphere, Atmos. Chem. Phys., 6, 575-599, doi:10.5194/acp-6-575-2006, 2006.

Hunke, E. and Dukowicz, J. K.: An elastic-viscous-plastic model for sea ice dynamics, J. Phys. Oceanogr., 27, 1849-1867, 1997.

Hibbard, K. A., Meehl, G. A., Cox, P., and Friedlingstein, P.:
A strategy for climate change stabilization experiments, EOS, T. Ame. Geophys. Union, 88(20), doi:10.1029/2007EO200002, 2007.

Hill, C., DeLuca, C., Balaji, V., Suarez, M., and Da Silva, A.: The architechture of the earth system modeling framework, Comput. Sci. Eng., 6, 18-28, 2004.

Hines, C. O.: Doppler-spread parameterization of gravity wave momentum deposition in the middle atmosphere, Part 2: Broad and quasi monochromatic spectra, and implementation, J. Atmos. Solar Terr. Phys., 59, 387-400, 1997.

Houghton, R. A., Hobbie, J. E., Melillo, J. M., Moore, B., Peterson, B. J., Shaver, G. R., and Woodwell, G. M.: Changes in the Carbon Content of Terrestrial Biota and Soils between 1860 and 1980 - a Net Release of $\mathrm{CO}_{2}$ to the Atmosphere, Ecol. Monogr., 53, 235-262, 1983.

Hurtt, G. C., Chini, L. P., Frolking, S., Betts, R., Feddema, J., Fischer, G., Goldewijk, K. K., Hibbard, K., Janetos, A., Jones, C., Kindermann, G., Kinoshita, T., Riahi, K., Shevliakova, E., Smith, S., Stehfest, E., Thomson, A., Thornton, P., van Vuuren, D., and Wang, Y. P.: Harmonisation of global land-use scenarios for the period 1500-2100 for IPCC-AR5, iLEAPS Newsletter, 6-8, 2009.

IGBP-DIS (International Geosphere-Biosphere Program, Data and Information Services): Global Soil Data Products, available at: http://daac.ornl.gov/SOILS/guides/igbp-surfaces.html, last access: 2010, 2000.

IPCC: in Climate Change 2007: The Physical Science Basis, Contribution of Working Group I to the Fourth Assessment Report of the Intergovernmental Panel on Climate Change, edited by: Solomon, S., Qin, D., Manning, M., Chen, Z., Marquis, M., Averyt, K. B., Tignor, M., and Miller, H. L., Cambridge University Press, Cambridge and New York, 2007.

Ise, T. and Sato, H.: Representing subgrid-scale edaphic heterogeneity in a large-scale ecosystem model: A case study in the circumpolar boreal regions, Geophys. Res. Lett., 35, L20407, doi:10.1029/2008g1035701, 2008.

Ise, T., Hajima, T., Sato, H., and Kato, T.: Simulating the twoway feedback between terrestrial ecosystems and climate: Importance of forest ecological processes on global change, in: Forest Canopies: Forest Production, Ecosystem Health, and Climate Conditions, edited by: Creighton, J. D. and Roney, P. J., NOVA, New York, 111-126, 2009.

Ito, A.: Climate-related uncertainties in projections of the twenty-first century terrestrial carbon budget: off-line model experiments using IPCC greenhouse-gas scenarios and AOGCM climate projections, Clim. Dynam., 24, 435-448, doi:10.1007/s00382-004-0489-7, 2005.

Jenkin, M. E., Saunders, S. M., and Pilling, M. J.: The tropospheric degradation of volatile organic compounds: A protocol for mechanism development, Atmos. Environ., 31, 81-104, 1997.

Jobbagy, E. G. and Jackson, R. B.: The vertical distribution of soil organic carbon and its relation to climate and vegetation, Ecol. Appl., 10, 423-436, 2000.

Jones, P. D., New, M., Parker, D. E., Martin, S., and Rigor, I. G.: Surface air temperature and its changes over the past 150 years, Rev. Geophys., 37, 173-199, 1999.

K-1 model developers: K-1 Coupled GCM (MIROC) Description, K-1 Technical Report No.1, Center for Climate System Research (Univ. of Tokyo), National Institute for Environmental 
Studies, and Frontier Research Center for Global Change, available at: http://www.ccsr.u-tokyo.ac.jp/kyosei/hasumi/MIROC/ tech-repo.pdf (last access: 30 September 2011), 2004.

Kato, T., Ito, A., and Kawamiya, M.: Multiple temporal scale variability during the twentieth century in global carbon dynamics simulated by a coupled climate-terrestrial carbon cycle model, Clim. Dynam., 32, 901-923, doi:10.1007/s00382-009-0548-1, 2009.

Kawamiya, M., Kishi, M. J., and Suginohara, N.: An ecosystem model for the North Pacific embedded in a general circulation model Part II: Mechanisms forming seasonal variations of chlorophyll, J. Marine Systems, 25, 159-178(20), 2000.

Kawamiya, M., Yoshikawa, C., Kato, T., Sato, H., Sudo, K., Watanabe, S., and Matsuno, T.: Development of an Integrated Earth System Model on the Earth Simulator, J. Earth Sim., 4, 18-30, 2005.

Kawase, H., Nagashima, T., Sudo, K., and Nozawa, T.: Future changes in tropospheric ozone under Representative Concentration Pathways (RCPs), Geophys. Res. Lett., 38, L05801, doi:10.1029/2010GL046402, 2011.

Kindermann, G. E., Mcallum, I., Fritz, S., and Obersteiner, M.: A global forest growing stock, biomass and carbon map based on FAO statistics, Silva Fennica, 42, 387-396, 2008.

Krinner, G., Viovy, N., de Noblet-Ducoudre, N., Ogee, J., Polcher, J., Friedlingstein, P., Ciais, P., Sitch, S., and Prentice, I. C.: A dynamic global vegetation model for studies of the coupled atmosphere-biosphere system, Global Biogeochem. Cy., 19, 1015, doi:10.1029/2003gb002199, 2005.

Lamarque, J.-F., Bond, T. C., Eyring, V., Granier, C., Heil, A., Klimont, Z., Lee, D., Liousse, C., Mieville, A., Owen, B., Schultz, M. G., Shindell, D., Smith, S. J., Stehfest, E., Van Aardenne, J., Cooper, O. R., Kainuma, M., Mahowald, N., McConnell, J. R., Naik, V., Riahi, K., and van Vuuren, D. P.: Historical (1850-2000) gridded anthropogenic and biomass burning emissions of reactive gases and aerosols: methodology and application, Atmos. Chem. Phys., 10, 7017-7039, doi:10.5194/acp10-7017-2010, 2010.

Landgraf, J. and Crutzen, P. J.: An efficient method for online calculations of photolysis and heating rates, J. Atmos. Sci., 55, 863878, 1998.

Lean, J., Rottman, G., Harder, J., and Kopp, G.: SORCE contributions to new understanding of global change and solar variability, Solar Phys., 230, 27-53, 2005.

Lenton, A., Codron, F., Bopp, L., Metzl, N., Cadule, P., Tagliabue, A., and Le Sommer, J.: Stratospheric ozone depletion reduces ocean carbon uptake and enhances ocean acidification, Geophys. Res. Lett., 36, L12606, doi:10.1029/2009GL038227, 2009.

Le Treut, H. and Li, Z.-X.: Sensitivity of an atmospheric general circulation model to prescribed SST changes: feedback effects associated with the simulation of cloud optical properties, Clim. Dynam., 5, 175-187, 1991.

Le Quéré, C., Rödenbeck, C., Buitenhuis, E. T., Conway, T. J., Langenfelds, R., Gomez, A., Labuschagne, C., Ramonet, M., Nakazawa, T., Metzl, N., Gillett, N., Heimann, M.: Saturation of the Southern Ocean $\mathrm{CO}_{2}$ sink due to recent climate change, Science, 316, 1735-1738, doi:10.1126/science.1136188, 2007.

Liu, X., Chance, K., Sioris, C. E., Spurr, R. J. D., Kurosu, T. P., Martin, R. V., and Newchurch, M. J.: Ozone profile and tropospheric ozone retrievals from the Global Ozone Monitoring
Experiment: Algorithm description and validation. J. Geophys. Res., 110, D20307, doi:10.1029/2005JD006240, 2005.

Mickley, L. J., Jacob, D. J., and Rind, D.: Uncertainty in preindustrial abundance of tropospheric ozone: implications for radiative forcing calculations, J. Geophys. Res., 106(D4), 3389-3399, doi:10.1029/2000JD900594, 2001.

Mickley, L. J. Jacob, D. J., Field, B. D., and Rind, D.: Climate response to the increase in tropospheric ozone since preindustrial times: a comparison between ozone and equivalent $\mathrm{CO}_{2}$ forcings, J. Geophys. Res., 109, D05106, doi:10.1029/2003JD003653, 2004.

Liu, X., Chance, K., Sioris, C. E., Kurosu, T. P., Spurr, R. J. D., Martin, R. V., Fu, T.-M., Logan, J. A., Jacob, D. J., Palmer, P. I., Newchurch, M. J., Megretskaia, I. A., and Chatfield, R. B.: First directly retrieved global distribution of tropospheric column ozone from GOME: Comparison with GEOSCHEM model, J. Geophys. Res., 111, D02301, doi:10.1029/2005JD006564, 2006.

Matthews, H. D., Weaver, A. J., and Meissner, K. J.: Terrestrial carbon cycle dynamics under recent and future climate change, J. Climate, 18, 1609-1628, 2005.

McFarlane, N. A.: The effect of orographically excited gravity wave drag on the general circulation of the lower stratosphere and troposphere, J. Atmos. Sci., 44, 1775-1800, 1987.

Meehl, G. A. and Hibbard, K. A.: A strategy for climate change stabilization experiments with AOGCMs and ESMs. WCRP Informal Report No. 3/2007, ICPO Publication No. 112, IGBP Report No. 57, World Climate Research Programme, Geneva, 35 pp., 2007.

Meinshausen, M., Smith, S., Calvin, K. V., Daniel, J. S., Kainuma, M., Lamarque, J.-F., Matsumoto, K., Montzka, S. A., Raper, S. C. B., Riahi, K., Thomson, A. M., Velders, G. J. M., and van Vuuren, D.: The RCP Greenhouse Gas Concentrations and their extension from 1765 to 2500, Clim. Change, doi:10.1007/s10584011-0156-z, 2011.

Meissner, K. J., Weaver, A. J., Matthews, H. D., and Cox, P. M.: The role of land surface dynamics in glacial inception: a study with the UVic Earth System Model, Clim. Dynam., 21, 515-537, doi:10.1007/s00382-003-0352-2, 2003.

Mellor, G. L. and Yamada, T.: A hierarchy of turbulence closure models for planetary boundary layers, J. Atmos. Sci., 31, 17911806, doi:10.1175/1520-0469 031<1791:AHOTCM>2.0.CO;2, 1974.

Mellor, G. L. and Yamada, T.: Development of a turbulence closure model for geostrophic fluid problems, Rev. Geophys., 20, 851875, doi:10.1029/RG020i004p00851, 1982.

Miyama, T. and Kawamiya, M.: Estimating allowable carbon emission for $\mathrm{CO}_{2}$ concentration stabilization using a GCMbased earth system model, Geophys. Res. Lett., 36, L19709, doi:10.1029/2009GL039678, 2009.

Moss, R. H., Edmonds, J. A., Hibbard, K. A., Manning, M. R., Rose, S. K., van Vuuren, D. P., Carter, T. R., Emori, S., Kainuma, M., Kram, T., Meehl, G. A., Mitchell, J. F. B., Nakicenovic, N., Riahi, K., Smith, S. J., Stouffer, R. J., Thomson, A. M., Weyant, J. P., and Wilbanks, T. J.: The next generation of scenarios for climate change research and assessment, Nature, 463, 747-756, doi:10.1038/nature08823, 2010.

Myneni, R. B., Hoffman, S., Knyazikhin, Y., Privette, J. L., Glassy, J., Tian, Y., Wang, Y., Song, X., Zhang, Y., Smith, G. R., Lotsch, A., Friedl, M., Morisette, J. T., Votava, P., Nemani, R. R., and 
Running, S. W.: Global products of vegetation leaf area and fraction absorbed PAR from year one of MODIS data, Remote Sens. Environ., 83, 214-231, 2002.

Nagashima, T., Takahashi, M., Takigawa, M., and Akiyoshi, H.: Future development of the ozone layer calculated by a general circulation model with fully interactive chemistry, Geophys. Res. Lett., 29, 1162, doi:10.1029/2001GL014026, 2001.

Nenes, A., Pandis, S. N., and Pilinis, C.: ISORROPIA: A new thermodynamic equilibrium model for multiphase multicomponent inorganic aerosols, Aquat. Geoch., 4, 123-152, 1998.

Noh, Y., and Kim, H. J.: Simulations of temperature and turbulence structure of the oceanic boundary layer with the improved nearsurface process, J. Geophys. Res., 104, 15621-15634, 1999.

Nozawa, T., Nagashima, T., Ogura, T., Yokohata, T., Okada, N., and Shiogama, H.: Climate change simulations with a coupled ocean-atmosphere GCM called the Model for Interdisciplinary Research on Climate: MIROC, CGER Supercomput. Monogr. Rep., 12, Cent. For Global Environ. Res., Natl. Inst. for Environ. Stud., Tsukuba, Japan, 2007.

Odum, J. R., Hoffmann, T., Bowman, F., Collins, D., Flagan, R. C., and Seinfeld, J. H.: Gas/Particle Partitioning and Secondary Organic Aerosol Yields, Environ. Sci. Technol., 30, 2580-2585, 1996.

Oki, T. and Sud, Y. C.: Design of Total Runoff Integrating Pathways (TRIP) - A Global River Channel Network, Earth Interact., 2, 137, 1998.

Oschlies, A.: Model-derived estimates of new production: New results point towards lower values, Deep-Sea Res. II, 48, $2173-$ 2197, 2001.

Pöschl, U., von Kuhlmann, R., Poisson, N., and Crutzen, P. J.: Development and intercomparison of condensed isoprene oxidation mechanisms for global atmospheric modeling, J. Atmos. Chem., 37, 29-52, 2000.

Post, W. M., Emanuel, W. R., Zinke, P. J., and Stangenberger, A. G.: Soil Carbon Pools and World Life Zones, Nature, 298, 156-159, 1982.

Prentice, I. C., Farquhar, G. D., Fasham, M. J. R., Goulden, M. L., Heimann, M., Jaramillo, V. J., Kheshgi, H. S., Le Quéré, C., Scholes, R. J., and Wallace, D. W. R.: The carbon cycle and atmospheric carbon dioxide, in: Climate change 2001: The Scientific basis. Contributions of working group I to the Third Assessment Report of the Intergovernmental Panel on Climate Change, edited by: Houghton, J. T., Ding, Y., Griggs, D. J., Noguer, M., van der Linden, P. J., Dai, X., Maskell, K., and Johnson, C. A., Cambridge University Press, Cambridge, United Kingdom, 183238, 2001

Purves, D. and Pacala, S.: Predictive models of forest dynamics, Science, 320, 1452-1453, doi:10.1126/science.1155359, 2008.

Redler, R., Valcke, S., and Ritzdorf, H.: OASIS4 - a coupling software for next generation earth system modelling, Geosci. Model Dev., 3, 87-104, doi:10.5194/gmd-3-87-2010, 2010.

Reynolds, R. W., Rayner, N. A., Smith, T. M., Stokes, D. C., and Wang, W.: An improved in situ and satellite SST analysis for climate, J. Climate, 15, 1609-1625, 2002.

Sarmiento, J. L. and Gruber, N.: Sinks for anthropogenic carbon, Phys. Today, 55, 30-36, 2002.

Sato, H.: Simulation of the vegetation structure and function in a Malaysian tropical rain forest using the individual-based dynamic vegetation model SEIB-DGVM, Forest Ecol. Manage.,
257, 2277-2286, doi:10.1016/j.foreco.2009.03.002, 2009.

Sato, H., Itoh, A., and Kohyama, T.: SEIB-DGVM: A new dynamic global vegetation model using a spatially explicit individual-based approach, Ecol. Modell., 200, 279-307, doi:10.1016/j.ecolmodel.2006.09.006, 2007.

Sato, H., Kobayashi, H., and Delbart, N.: Simulation study of the vegetation structure and function in eastern Siberian larch forests using the individual-based vegetation model SEIB-DGVM, Forest Ecol. Manage., 259, 301-311, doi:10.1016/j.foreco.2009.10.019, 2010.

Sato, M., Hansen, J. E., McCormick, M. P., and Pollack, J. B.: Stratospheric aerosol optical depth, 1850-1990, J. Geophys. Res., 98, 22987-22994, 1993.

Sekiguchi, M. and Nakajima, T.: A k-distribution based radiation code and its computational optimization for an atmospheric general circulation model, J. Quant. Spectrosc. Radiat. Transfer, 109, 2779-2793, 2008.

Semtner Jr., A. J.: A model for the thermodynamic growth of sea ice in numerical investigations of climate, J. Phys. Oceanogr., 6, 379-389, 1976.

Shindell, D. T., Faluvegi, G., and Bell, N.: Preindustrial-to-presentday radiative forcing by tropospheric ozone from improved simulations with the GISS chemistry-climate GCM, Atmos. Chem. Phys., 3, 1675-1702, doi:10.5194/acp-3-1675-2003, 2003.

Shindell, D. T., Faluvegi, G., Bell, N., and Schmidt, G.: An emissions based view of climate forcing by methane and tropospheric ozone, Geophys. Res. Lett., 32, L04803, doi:10.1029/2004GL021900, 2005.

Sitch, S., Smith, B., Prentice, I. C., Arneth, A., Bondeau, A., Cramer, W., Kaplan, J. O., Levis, S., Lucht, W., Sykes, M. T., Thonicke, K., and Venevsky, S.: Evaluation of ecosystem dynamics, plant geography and terrestrial carbon cycling in the LPJ dynamic global vegetation model, Glob. Change Biol., 9, 161$185,2003$.

Sitch, S., Cox, P. M., Collins, W. J., and Huntingford, C.: Indirect radiative forcing of climate change through ozone effects on the land-carbon sink, Nature, 448, 791-795, doi:10.1038/nature06059, 2007.

Sitch, S., Huntingford, C., Gedney, N., Levy, P. E., Lomas, M., Piao, S. L., Betts, R., Ciais, P., Cox, P., Friedlingstein, P., Jones, C. D., Prentice, I. C., and Woodward, F. I.: Evaluation of the terrestrial carbon cycle, future plant geography and climate-carbon cycle feedbacks using five Dynamic Global Vegetation Models (DGVMs), Glob. Change Biol., 14, 2015-2039, doi:10.1111/j.1365-2486.2008.01626.x, 2008.

Solomon, S., Rosenlof, K. H., Portmann, R. W., Daniel, J. S., Davis, S. M., Sanford, T. J., and Plattner, G.-K.: Contributions of Stratospheric Water Vapor to Decadal Changes in the Rate of Global Warming, Science, 327, 1219-1223, doi:10.1126/science.1182488, 2010.

Sudo, K. and Akimoto, H.: Global source attribution of tropospheric ozone: Long-range transport from various source regions, J. Geophys. Res., 112, D12302, doi:10.1029/2006JD007992, 2007

Sudo, K., Takahashi, M., Kurokawa, J., and Akimoto, H.: CHASER: A global chemical model of the troposphere 1. Model description, J. Geophys. Res., 107, 4339, doi:10.1029/2001JD001113, 2002a.

Sudo, K., Takahashi, M., and Akimoto H., CHASER: A global 
chemical model of the troposphere 2. Model results and evaluation, J. Geophys. Res., 107, 4586, doi:10.1029/2001JD001114, $2002 b$.

Sudo, K., Takahashi, M., and Akimoto, H.: Future changes in stratosphere-troposphere exchange and their impacts on fugure tropospheric simulations, Geophys. Res. Lett., 30, 2256, doi:10.1029/2003GL018526, 2003.

Sudo, K., Takata, K., Takemura, T., Kanzawa, H., and Yasunari, T.: Coupled effects of land use and aerosols changes and their impacts on Asian climate, Low Temp. Sci., 68, 129-136, 2010.

Suzuki, R., Xu J., and Motoya, K.: Global Analyses of Satellitederived Vegetation Index Related to Climatological Wetness and Warmth, Int. J. Climatol., 26, 425-438, 2006.

Takata, K., Emori, S., and Watanabe, T.: Development of the minimal advanced treatments of surface interaction and runoff, Global Planet. Change, 38, 209-222, doi:10.1016/S09218181(03)00030-4, 2003.

Takemura, T., Okamoto, H., Maruyama, Y., Numaguti, A., Higurashi, A., and Nakajima, T.: Global three-dimensional simulation of aerosol optical thickness distribution of various origins, J. Geophys. Res., 105, 17853-17873, 2000.

Takemura, T., Nakajima, T., Dubovik, O., Holben, B. N., and Kinne, S.: Single-scattering albedo and radiative forcing of various aerosol species with a global three-dimensional model, J. Climate, 15, 333-352, 2002.

Takemura, T., Nozawa, T., Emori, S., Nakajima, T. Y., and Nakajima, T.: Simulation of climate response to aerosol direct and indirect effects with aerosol transport-radiation model, J. Geophys. Res., 110, D02202, doi:10.1029/2004JD005029, 2005.

Takemura, T., Egashira, M., Matsuzawa, K., Ichijo, H., O'ishi, R., and Abe-Ouchi, A.: A simulation of the global distribution and radiative forcing of soil dust aerosols at the Last Glacial Maximum, Atmos. Chem. Phys., 9, 3061-3073, doi:10.5194/acp-93061-2009, 2009.

Tarnocai, C., Canadell, J. G., Schuur, E. A. G., Kuhry, P., Mazhitova, G., and Zimov, S.: Soil organic carbon pools in the northern circumpolar permafrost region, Global Biogeochem. Cy., 23, GB2023, doi:10.1029/2008GB003327, 2009.

Taylor, K. E., Stouffer, R. J., and Meehl, G. A.: A summary of the CMIP5 experimental design, retrieved on: 8 April 2010, available at: http://cmip-pcmdi.llnl.gov/cmip5/experiment_design. html?submenuheader $=1,2009$.

Tjiputra, J. F., Assmann, K., Bentsen, M., Bethke, I., Otterå, O. H., Sturm, C., and Heinze, C.: Bergen Earth system model (BCM-C): model description and regional climate-carbon cycle feedbacks assessment, Geosci. Model Dev., 3, 123-141, doi:10.5194/gmd-3-123-2010, 2010.

Uppala, S. M., Kallberg, P. W., Simmons, A. J., Andrae, U., Costa Bechtold, V. D. A, Fiorino, M., Gibson, J. K., Haseler, J., Hernandez, A., Kelly, G. A., Li, X., Onogi, K., Saarinen, S., Sokka, N., Allan, R. P., Andersson, E., Arpe, K., Balmaseda, M. A., Beljaars, A. C. M., van de Berg, L., Bidlot, J., Bormann, N., Caires, S., Chevallier, F., Dethof, A., Dragosavac, M., Fisher, M., Fuentes, M., Hagemann, S., Holm, E., Hoskins, B. J., Isaksen, L., Janssen, P. A. E. M., Jenne, R., McNally, A. P., Mahfouf, J.-F., Morcrette, J.-J., Rayner, N. A., Saunders, R. W., Simon, P., Sterl, A., Trenberth, K. E., Untch, A., Vasiljevic, D., Viterbo, P., and Woollen, J.: The ERA-40 re-analysis, Q. J. R. Meteorol. Soc., 131, 2961-3012, doi:10.1256/qj.04.176, 2005.
Watanabe, S.: Constraints on a non-orographic gravity wave drag parameterization using a gravity wave resolving general circulation model, SOLA(Scientific Online Letters on the Atmosphere), 4, 61-64, doi:10.2151/sola.2008-016, 2008.

Watanabe, S. and Kawatani, Y., Sensitivity of the QBO to mean tropical upwelling under a changing climate, J. Metorol. Soc. Jpn., accepted, 2011.

Watanabe, S. and Yokohata, T.: Future Increase of All-sky UV-B over Asia Projected by an Earth System Model., J. Metorol. Soc. Jpn., accepted, 2011.

Watanabe, S., Miura, H., Sekiguchi, M., Nagashima, T., Sudo, K. Emori, S., and Kawamiya, M.: Development of an atmospheric general circulation model for integrated Earth system modeling on the Earth Simulator, J. Earth Simulator, 9, 27-35, 2008a.

Watanabe, S., Kawatani, Y., Tomikawa, Y., Miyazaki, K., Takahashi, M., and Sato, K.: General aspects of a T213L256 middle atmosphere general circulation model, J. Geophys. Res., 113, D12110, doi:10.1029/2008JD010026, 2008b.

Watanabe, S., Sudo, K., Nagashima, T., Takemura, T., Kawase, H., and Nozawa, T.: Future Projections of Surface UVB in a Changing Climate, J. Geophys. Res., 116, D16118, doi:10.1029/2011JD015749, 2011.

World Meteorological Organization (WMO): Scientific Assessment of Ozone Depletion: 2006, Rep. 50, Global Ozone Research and Monitoring Project, World Meteorol. Organ., Geneva, Switzerland, 2007.

Weaver, A. J., Eby, M., Wiebe, E. C., Bitz, C. M., Duffy, P. B., Ewen, T. L., Fanning, A. F., Holland, M. M., MacFadyen, A., Matthews, H. D., Meissner, K. J., Saenko O., Schmittner, A., Wang, H., and Yoshimori, M.: The UVic Earth System Climate Model: model description, climatology, and applications to past, present and future climates, Atmos. Ocean., 4, 361-428, 2001.

Yang, Z.-L., Dickinson, R. E., Robock, A., and Vinnikov, K. Ya.: Validation of the snow submodel of the Biosphere-Atmosphere Transfer Scheme with Russian snow cover and meteorological observational data, J. Clim., 10, 353-373, 1997.

Yokohata, T., Webb, M. J., Collins, M., Williams, K. D., Yoshimori, M., Hargreaves, J. C., and Annan, J. D.: Structural similarities and differences in climate responses to $\mathrm{CO}_{2}$ increase between two perturbed physics ensembles, J. Climate, 23, 1392-1410, doi:10.1175/2009JCLI2917.1, 2010.

Yoshikawa, C., Kawamiya, M., Kato, T., Yamanaka, Y., and Matsuno, T.: Geographical distribution of the feedback between future climate change and the carbon cycle, J. Geophys. Res., 113, G03002, doi:10.1029/2007JG000570, 2008.

Zhao, M. S., Heinsch, F. A., Nemani, R. R., and Running, S. W.: Improvements of the MODIS terrestrial gross and net primary production global data set, Remote Sens. Environ., 95, 164-176, doi:10.1016/j.rse.2004.12.011, 2005. 